\title{
Tuning State Energies for Narrow Blue Emission in Tetradentate Pyridyl-Carbazole Platinum Complexes
}

Tyler Fleetham, ${ }^{\sharp \S}$ Jessica H. Golden, ${ }^{\dagger \S}$ Muazzam Idris, Han-Ming Hau, Daniel Sylvinson Muthiah Ravinson, Peter I. Djurovich and Mark E. Thompson* Department of Chemistry, University of Southern California, Los Angeles, California, 90089, United States

* corresponding author: $\underline{\operatorname{met} @ \text { usc.edu }}$

† Current address: Universal Display Corporation, Ewing, New Jersey, 08618, United States

$\dagger$ Current address: Sepion Technologies, Inc., Emeryville, California, 94608, United States

$\S$ These authors contributed equally to this work. 


\section{Table of Contents}

Excitation spectra of PtNON derivatives................................................................................ 3

Figure S1. Excitation spectra of PtNON derivatives in PMMA at 298K (blue, squares) and in 2-MeTHF at RT

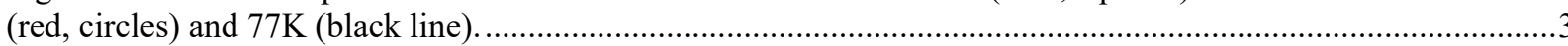

UV-Visible and Photoluminescence spectra of PtNON-OMe in different media ................... 4

Figure S2. UV-visible and luminescence spectra of PtNON-OMe in different media...........................................

PLQY of PtNON-OMe in different host matrices ................................................................ 4

Table S1. PLQY of PtNON-OMe in different host matrices ...................................................................................

OLED Fabrication and Characterization............................................................................5

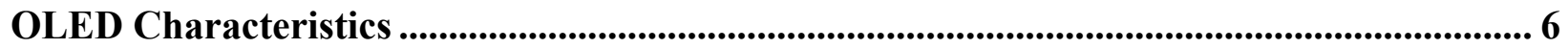

Figure S3. OLED device characteristics of PtNON-OMe in DPEPO host. (a) Device architecture and chemical formula of materials. (b) EL spectra. (c) J-V-L curves (d) Efficiency versus current curves ...............................6

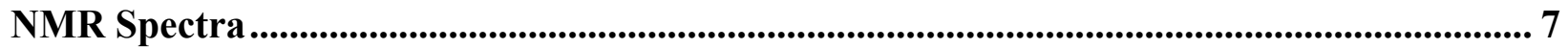

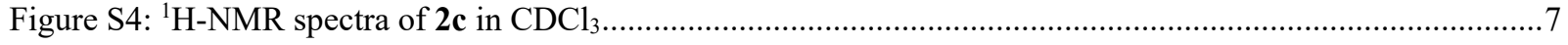

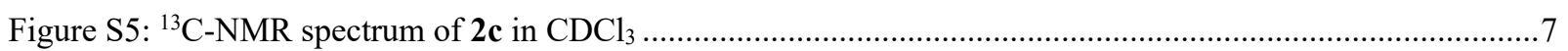

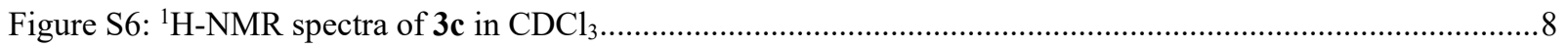

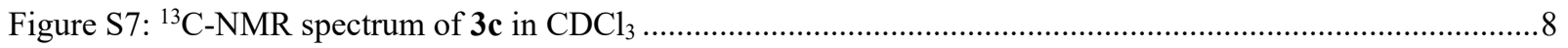

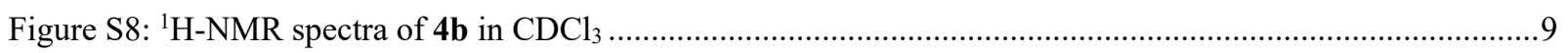

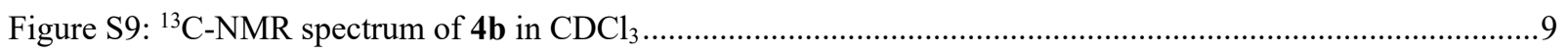

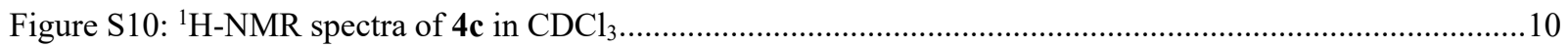

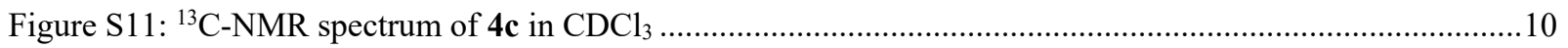

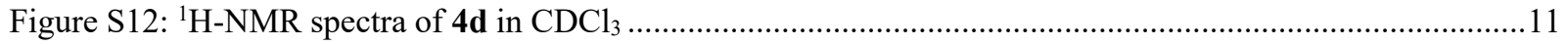

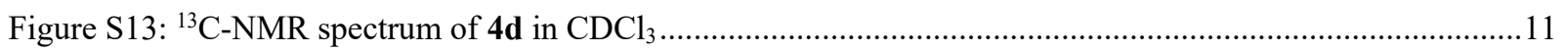

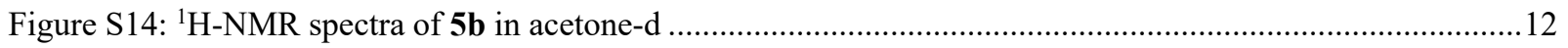

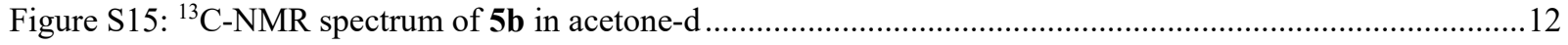

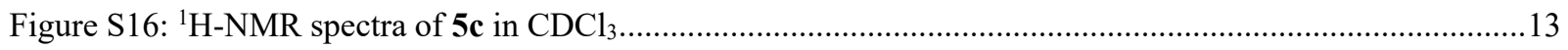

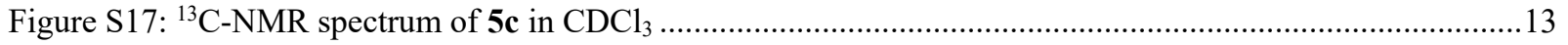

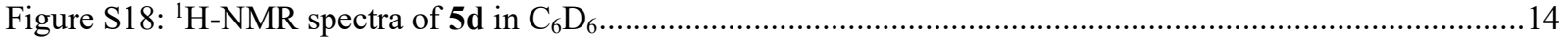

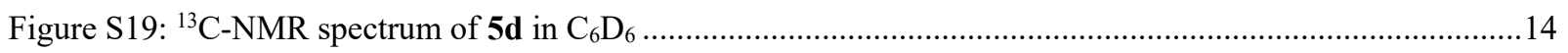

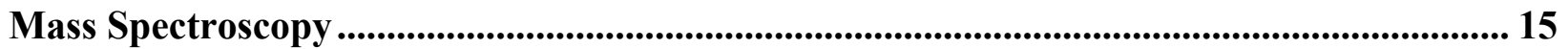

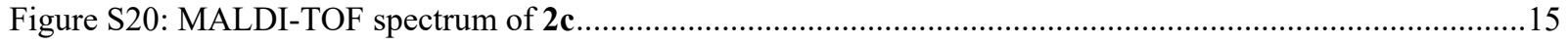

Figure S21: MALDI-TOF spectrum of 3c

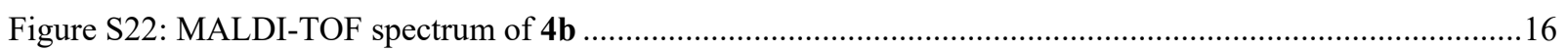

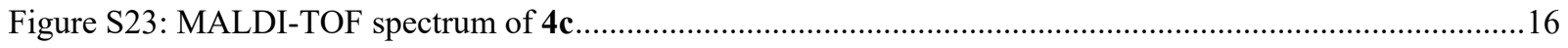

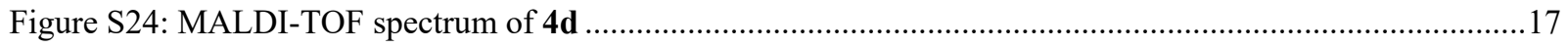

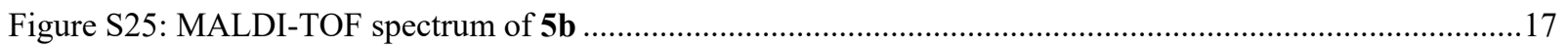

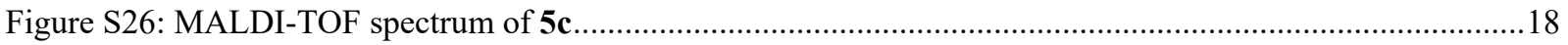

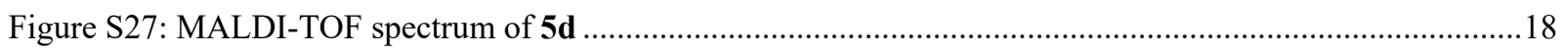




\section{Excitation spectra of PtNON derivatives}
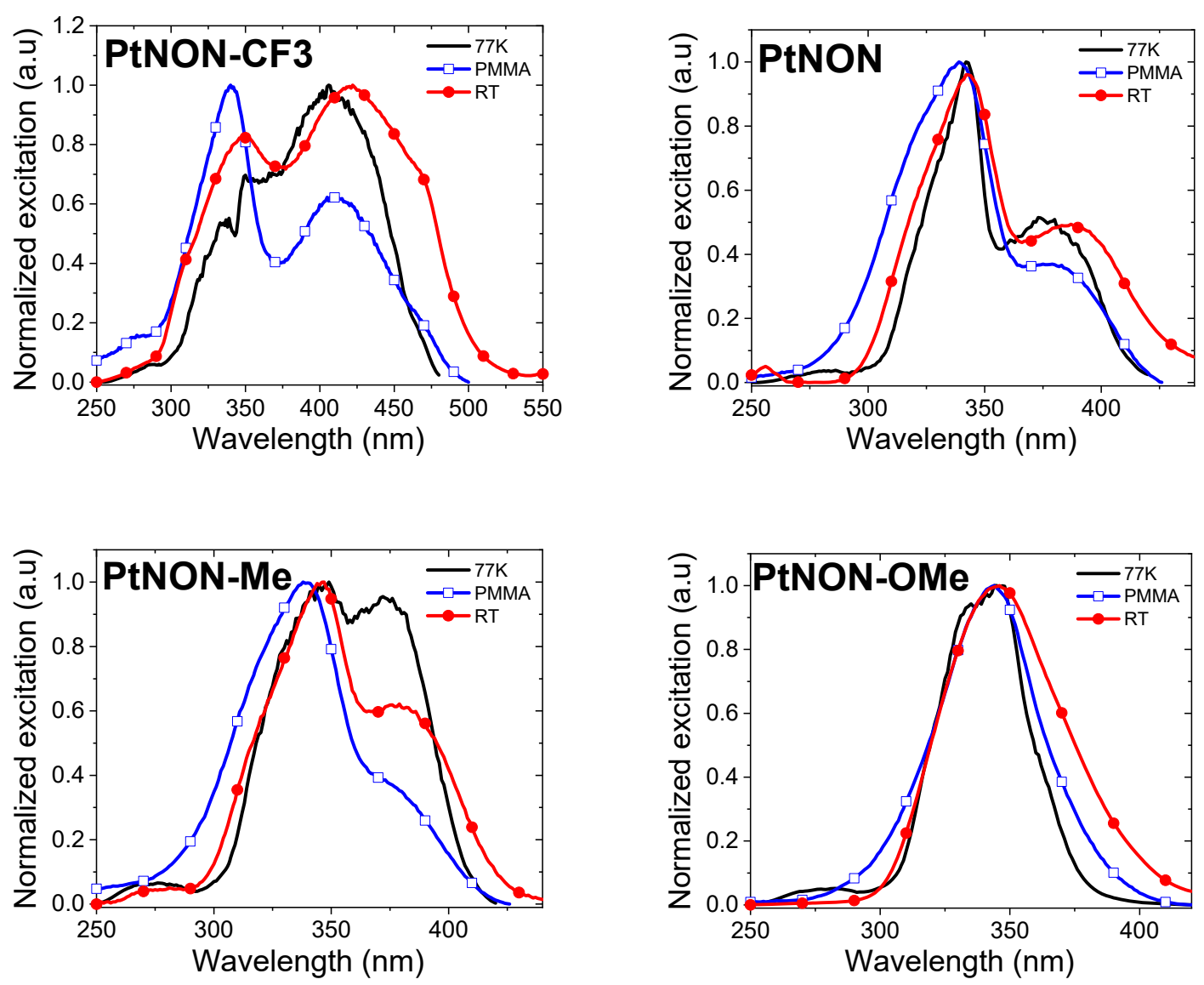

Figure S1. Excitation spectra of PtNON derivatives in PMMA at 298K (blue, squares) and in 2-MeTHF at RT (red, circles) and 77K (black line). 
UV-Visible and Photoluminescence spectra of PtNON-OMe in different media
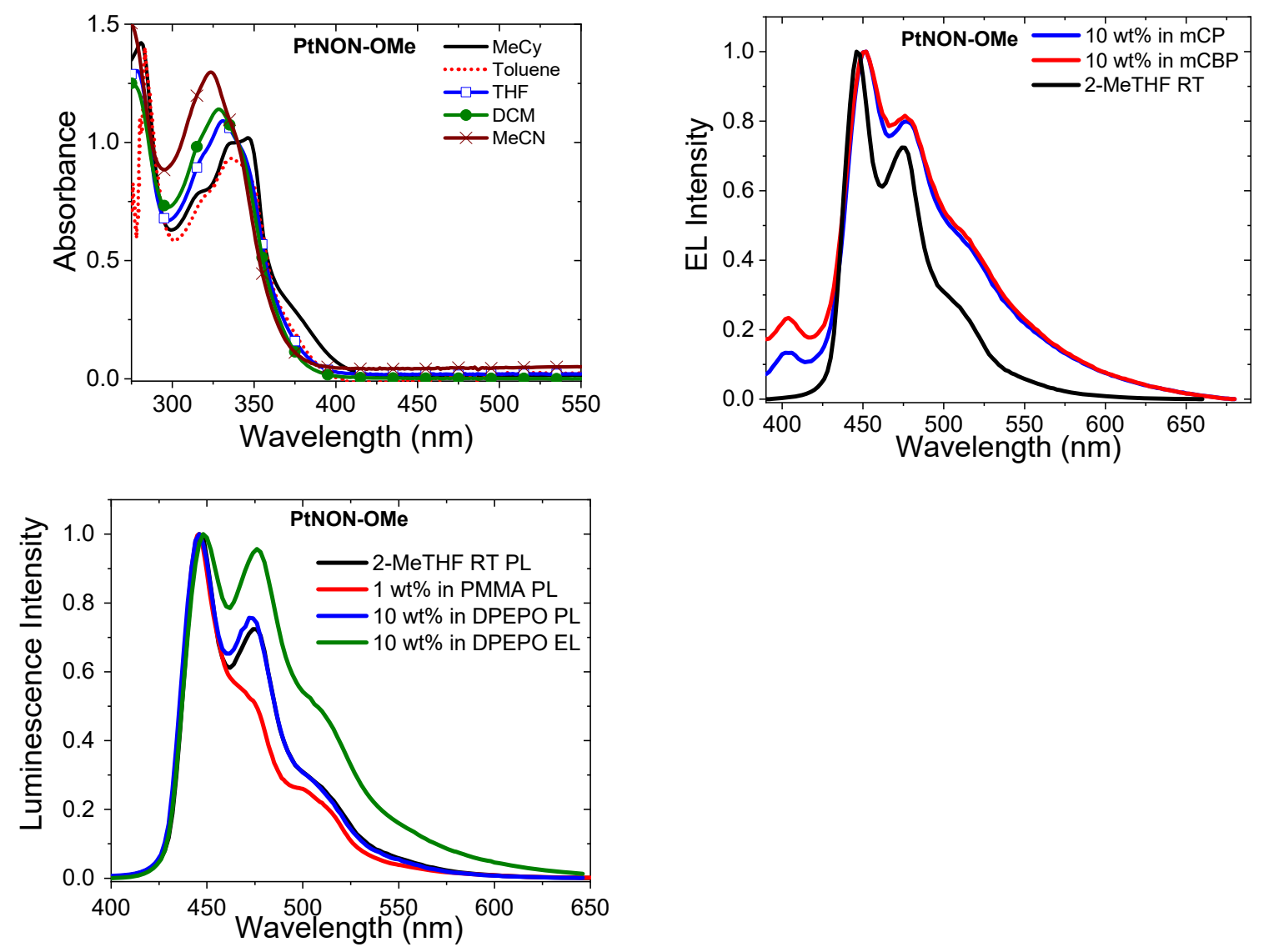

Figure S2. UV-visible and luminescence spectra of PtNON-OMe in different media.

\section{PLQY of PtNON-OMe in different host matrices}

Table S1. PLQY of PtNON-OMe in different host matrices

\begin{tabular}{|c|c|c|c|c|}
\hline & $1 w t \%$ in PMMA & 10wt \% in mCP & 10wt\% in $m$ CBP & 10wt\% in DPEPO \\
\hline PLQY & 0.69 & $<1$ & $<1$ & 0.45 \\
\hline
\end{tabular}




\section{OLED Fabrication and Characterization}

OLED devices were fabricated on pre-patterned ITO-coated glass substrates $\left(20 \pm 5 \Omega \mathrm{cm}^{-2}\right.$, Thin Film Devices, Inc.). Prior to deposition, the substrates were cleaned with soap, rinsed with deionized water and sonicated for 15 minutes. Afterwards, two subsequent rinses and 15-minute sonication baths were performed in acetone and isopropyl alcohol, followed by $10 \mathrm{~min}$ UV ozone exposure. Poly(3,4- ethylenedioxythiophene):polystyrene sulfonate (PEDOT:PSS, Sigma-Aldrich 655201) was filtered and spin-coated onto the substrates in air to form a $\sim 70 \mathrm{~nm}$ layer, and was annealed at $190{ }^{\circ} \mathrm{C}$ for 20 minutes under nitrogen atmosphere. The emissive layer $(10 \mathrm{wt} \%$ PtNON-OMe in DPEPO) was spin-coated from dichloromethane solution $(10 \mathrm{mg} / 3 \mathrm{ml})$ onto the PEDOT:PSS to form a layer of $\sim 30 \mathrm{~nm}$, followed by annealing at $95{ }^{\circ} \mathrm{C}$ for 10 min under nitrogen atmosphere. $\quad \sim 50 \quad \mathrm{~nm} \quad$ 2,2',2"-(1,3,5-Benzinetriyl)-tris(1-phenyl-1-H-benzimidazole) (TPBI, Sigma-Aldrich), LiF and Aluminum were deposited in a vacuum thermal evaporator, EVO Vac 800 deposition system from Angstrom Engineering, at $6 \times 10^{-7}$ Torr.

Current-voltage-luminescence ( $\mathrm{J}-\mathrm{V}-\mathrm{L})$ curves were using a Keithley power source meter model 2400 and a Newport multifunction optical model 1835-C, PIN-220DP/SB blue-enhanced silicon photodiodes (OSI optoelectronics Ltd.). The sensor was set to measure power at an energy of 520 $\mathrm{nm}$, followed by correcting to the average electroluminescence wavelength for each individual device during data process. Electroluminescence (EL) spectra of OLEDs were measured using the fluorimeter (model C-60 Photon Technology International QuantaMaster) at several voltages. 


\section{OLED Characteristics}

a)
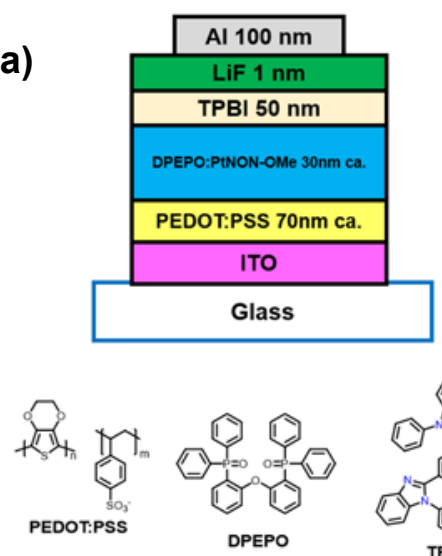

c) b)

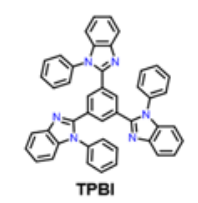

d)

Figure S3. OLED device characteristics of PtNON-OMe in DPEPO host. (a) Device architecture and chemical formula of materials. (b) EL spectra. (c) J-V-L curves (d) Efficiency versus current curves 


\title{
NMR Spectra
}

\author{
PROTON_01
}
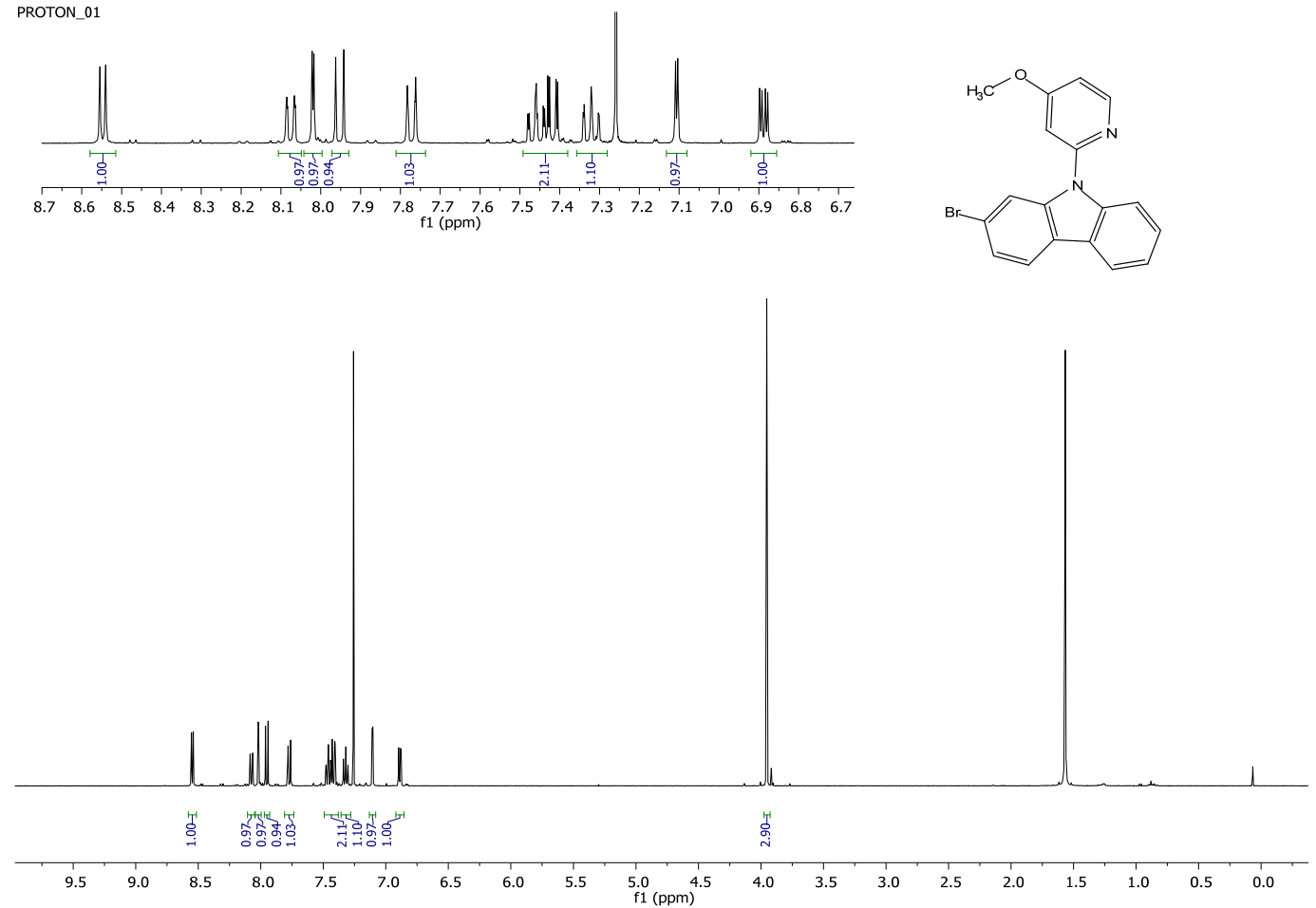

Figure S4: ${ }^{1} \mathrm{H}-\mathrm{NMR}$ spectra of $\mathbf{2 c}$ in $\mathrm{CDCl}_{3}$

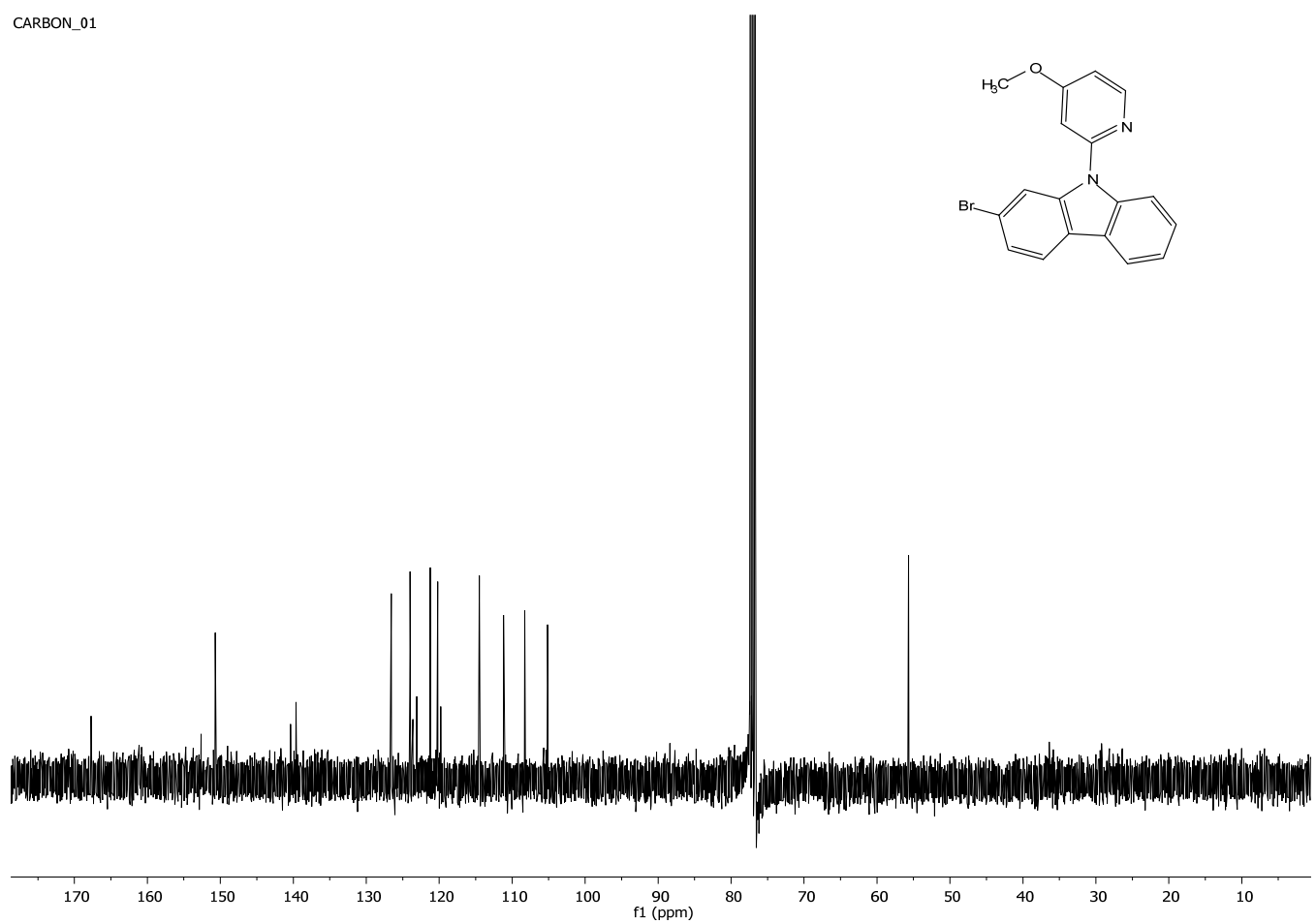

Figure S5: ${ }^{13} \mathrm{C}$-NMR spectrum of $\mathbf{2 c}$ in $\mathrm{CDCl}_{3}$ 


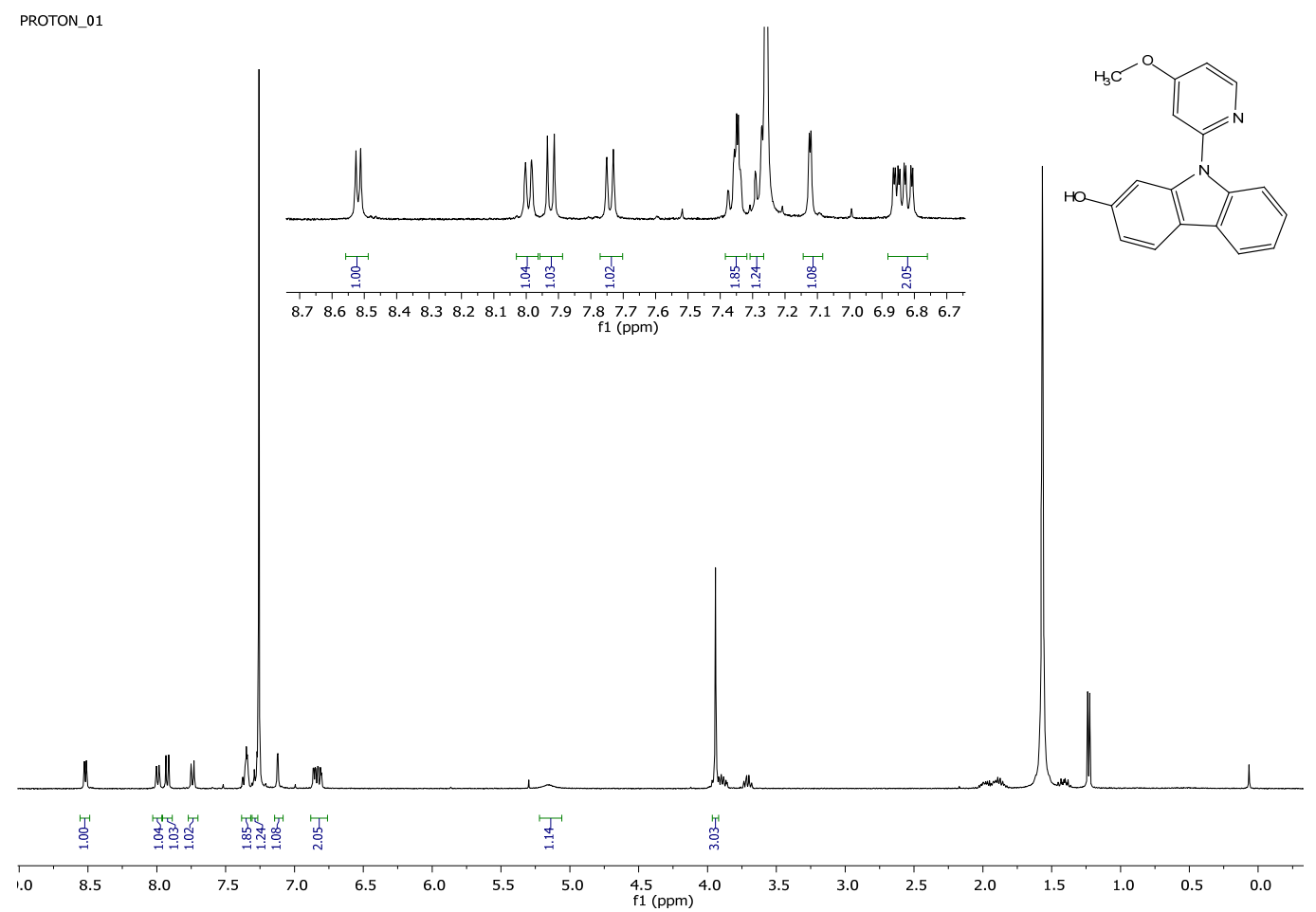

Figure S6: ${ }^{1} \mathrm{H}-\mathrm{NMR}$ spectra of $\mathbf{3 c}$ in $\mathrm{CDCl}_{3}$ CARBON_01

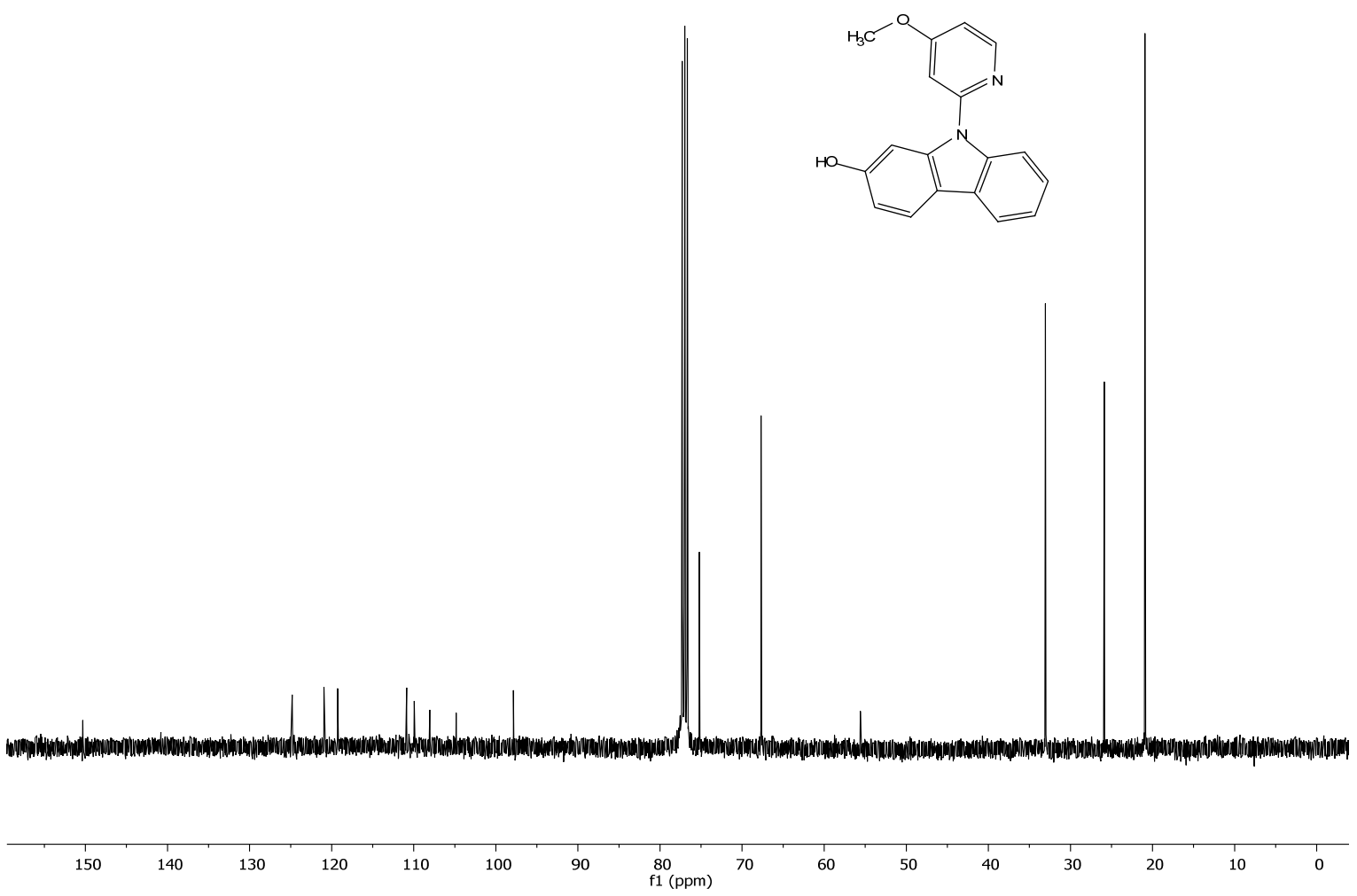

Figure S7: ${ }^{13} \mathrm{C}-\mathrm{NMR}$ spectrum of $\mathbf{3 c}$ in $\mathrm{CDCl}_{3}$ 
PROTON_01
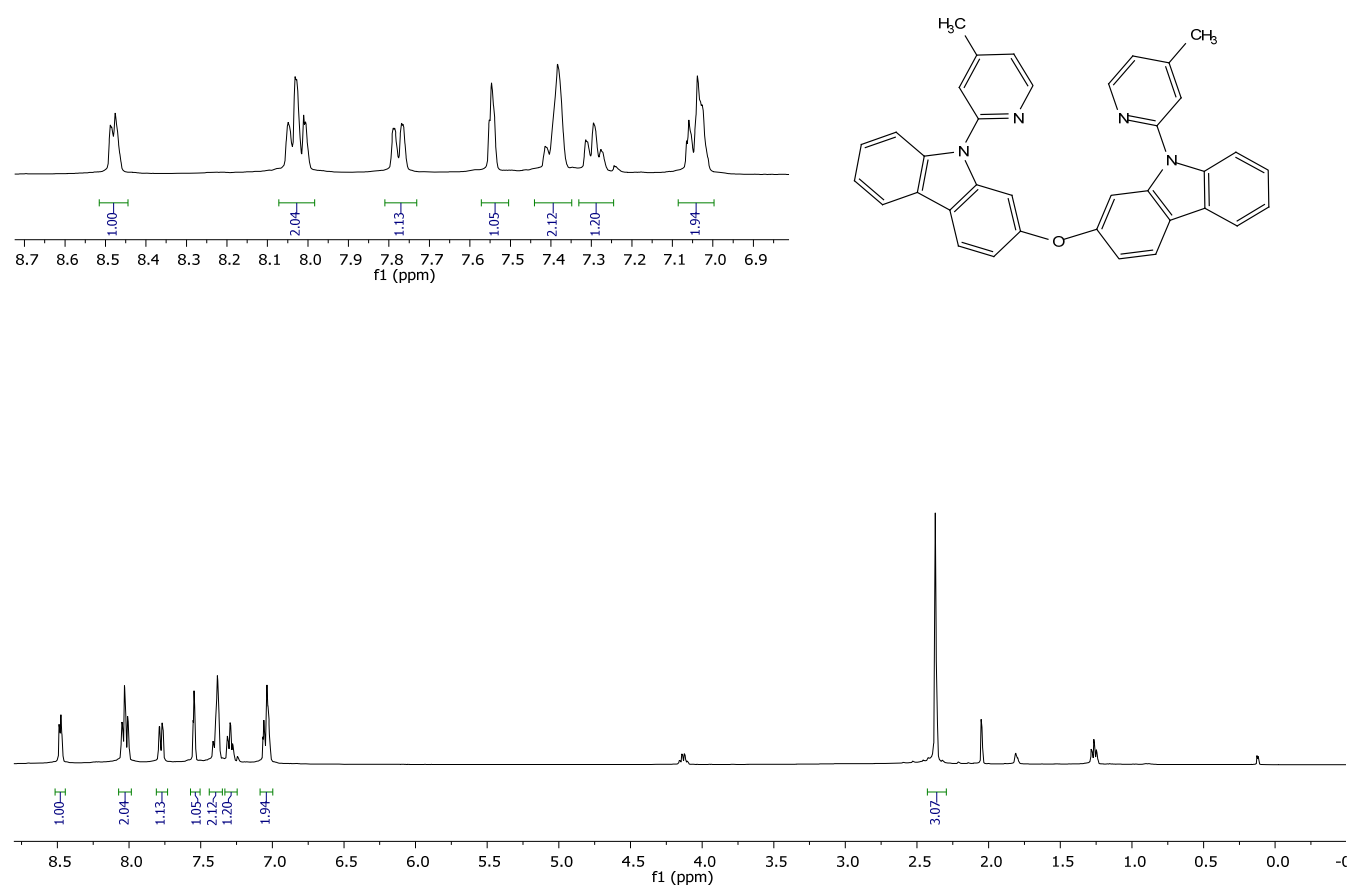

Figure S8: ${ }^{1} \mathrm{H}-\mathrm{NMR}$ spectra of $\mathbf{4 b}$ in $\mathrm{CDCl}_{3}$

CARBON_01
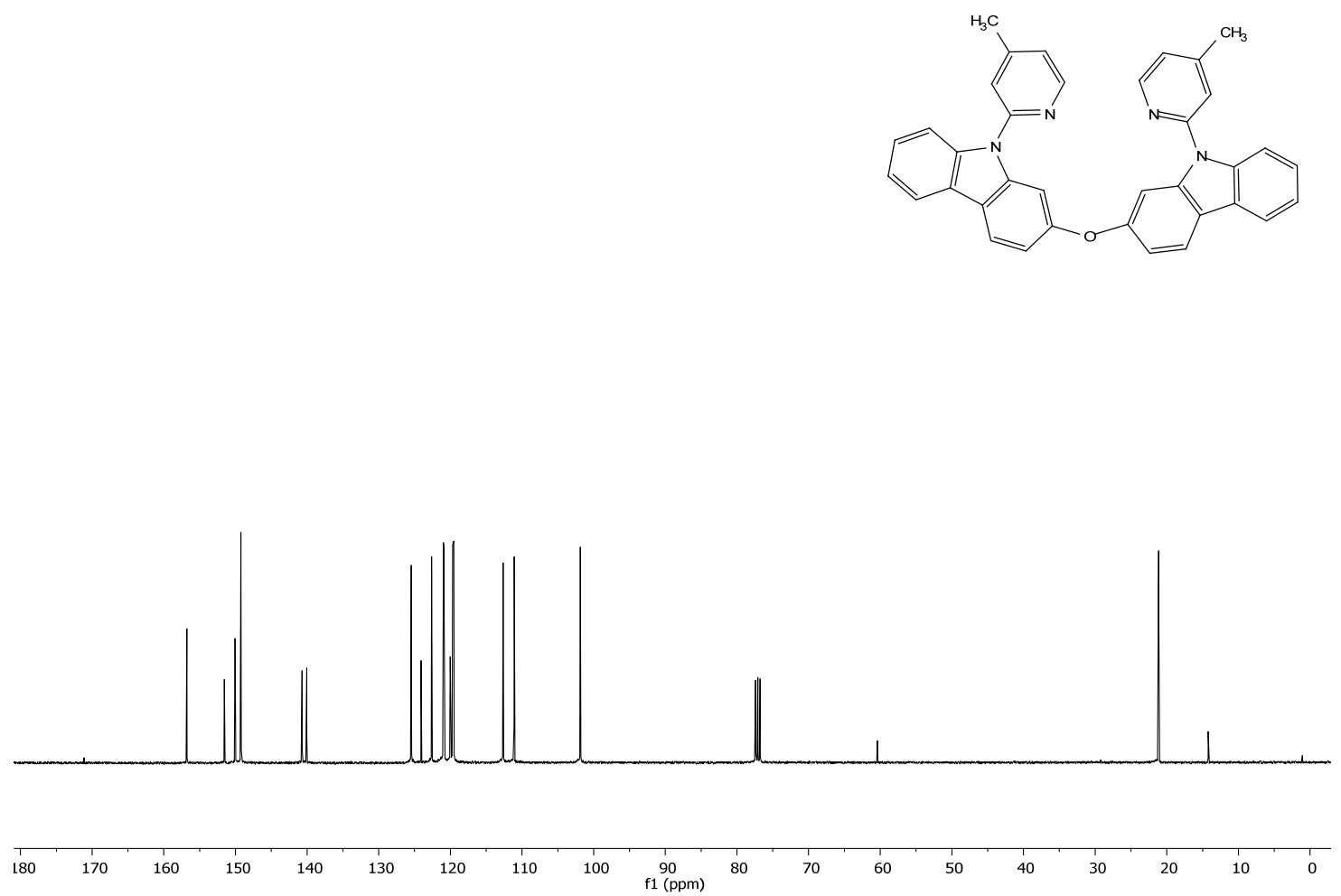

Figure S9: ${ }^{13} \mathrm{C}-\mathrm{NMR}$ spectrum of $\mathbf{4 b}$ in $\mathrm{CDCl}_{3}$ 


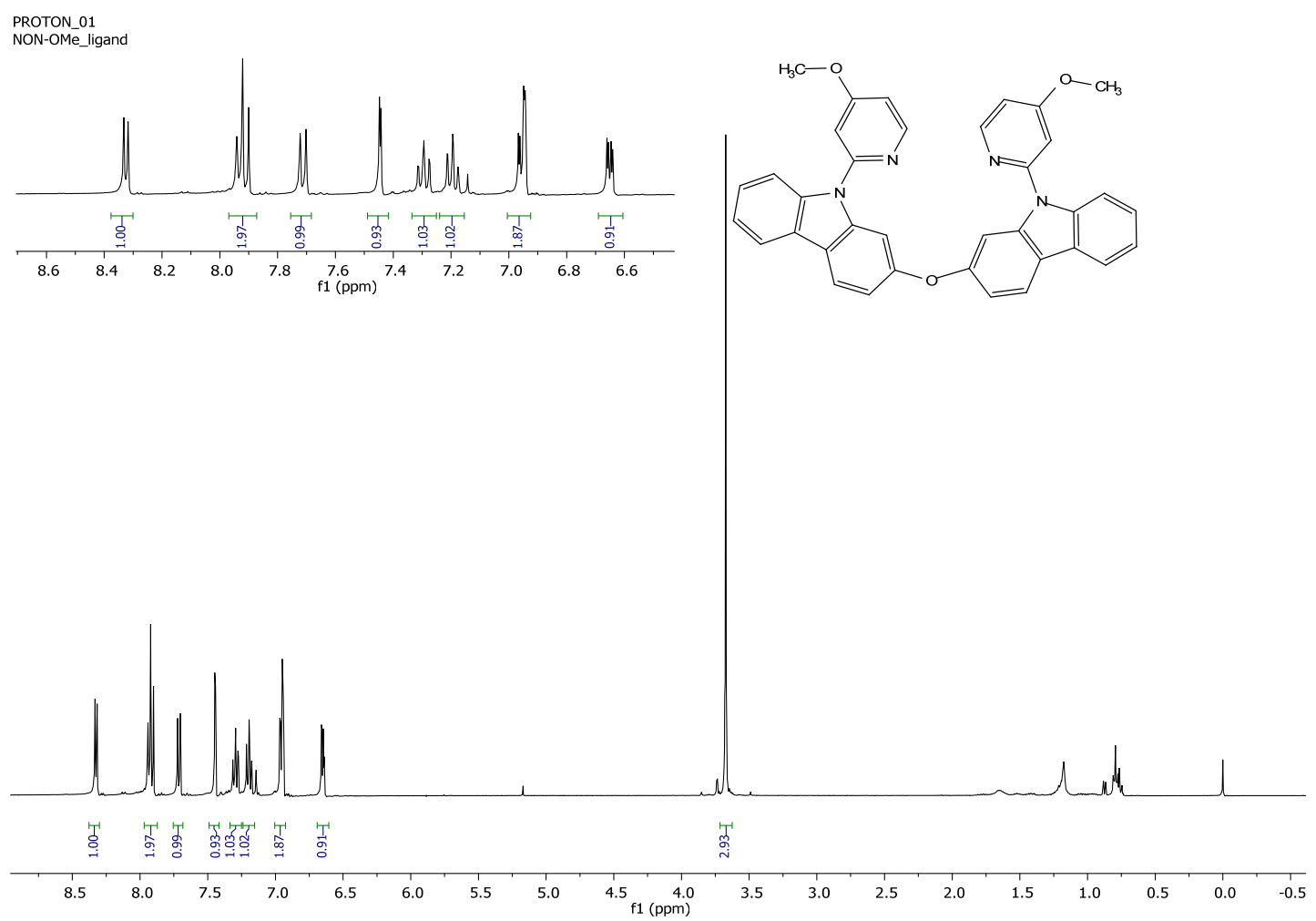

Figure S10: ${ }^{1} \mathrm{H}-\mathrm{NMR}$ spectra of $\mathbf{4 c}$ in $\mathrm{CDCl}_{3}$

CARBON_01
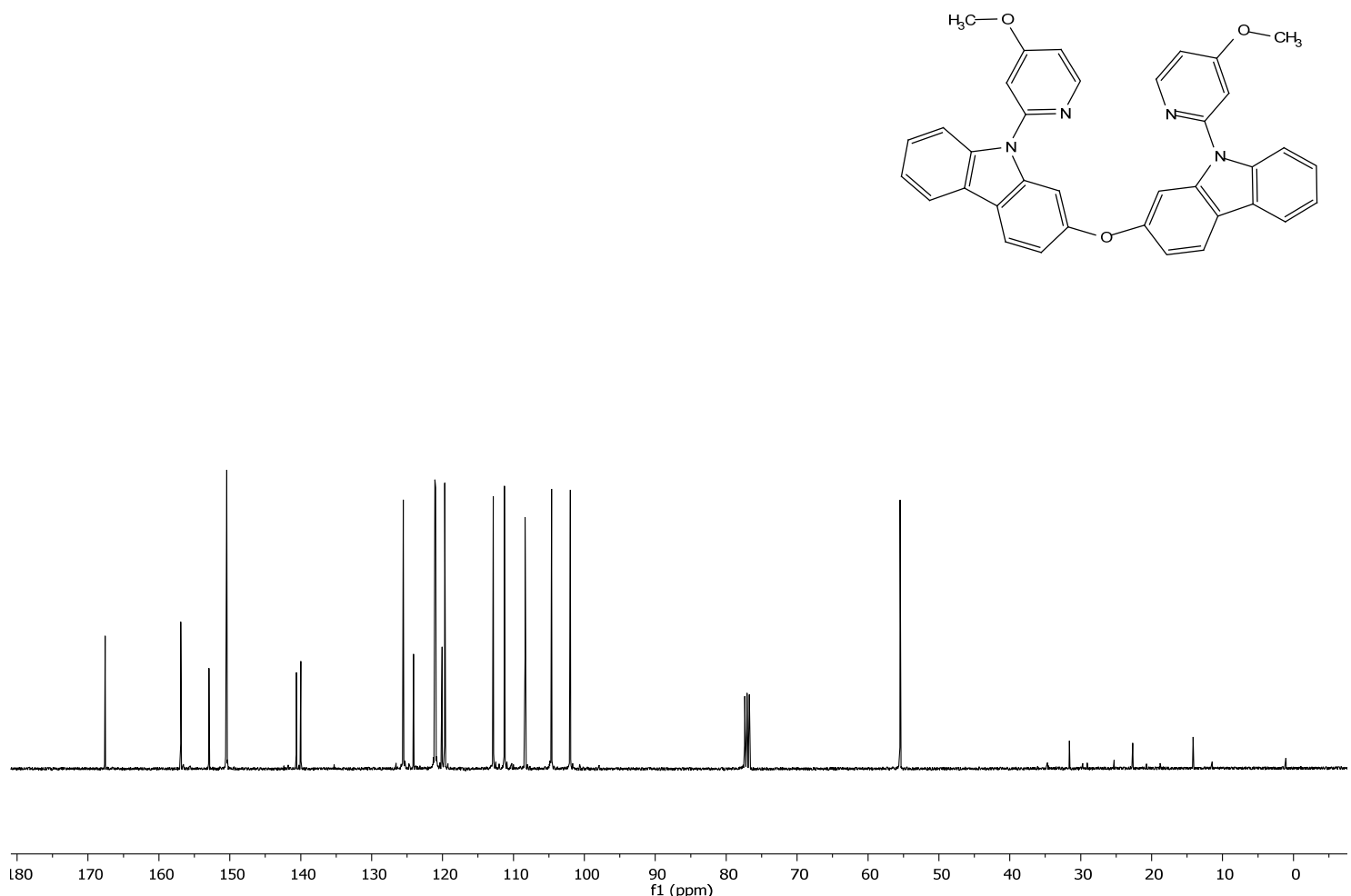

Figure S11: ${ }^{13} \mathrm{C}-\mathrm{NMR}$ spectrum of $\mathbf{4} \mathbf{c}$ in $\mathrm{CDCl}_{3}$ 
PROTON_01
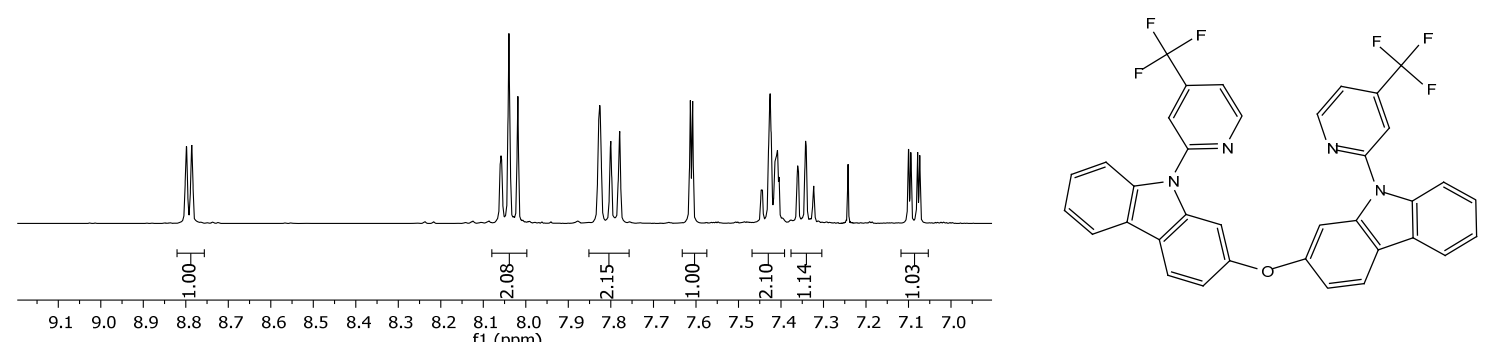

$\begin{array}{lllllllllllllllllllllllllllll}9.1 & 9.0 & 8.9 & 8.8 & 8.7 & 8.6 & 8.5 & 8.4 & 8.3 & 8.2 & 8.1 & 8.0 & 7.9 & 7.8 & 7.7 & 7.6 & 7.5 & 7.4 & 7.3 & 7.2 & 7.1 & 7.0 \\ \mathrm{f}(\mathrm{ppm})\end{array}$

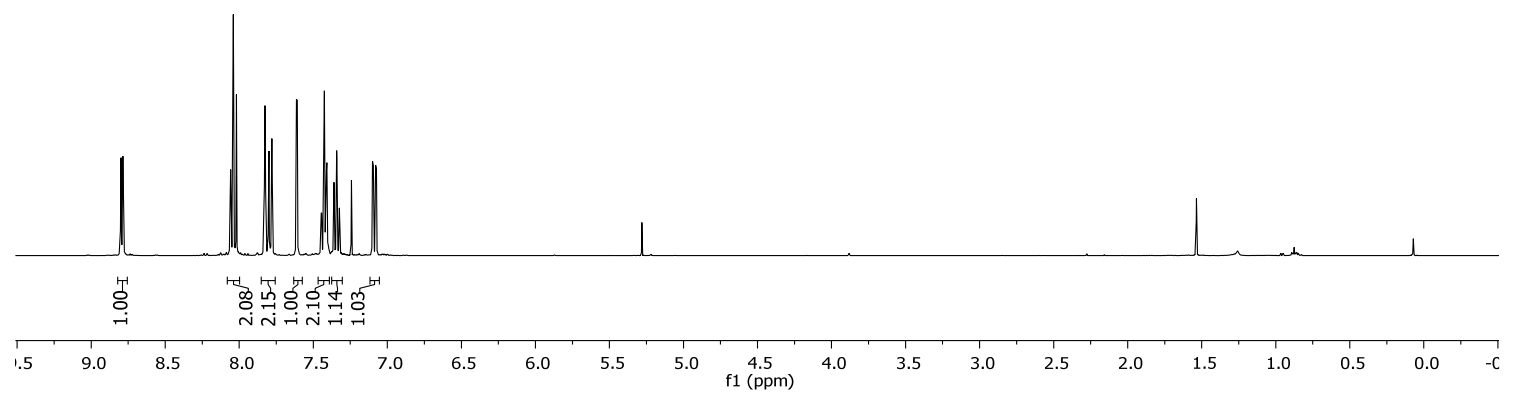

Figure S12: ${ }^{1} \mathrm{H}-\mathrm{NMR}$ spectra of $\mathbf{4 d}$ in $\mathrm{CDCl}_{3}$

CARBON_01
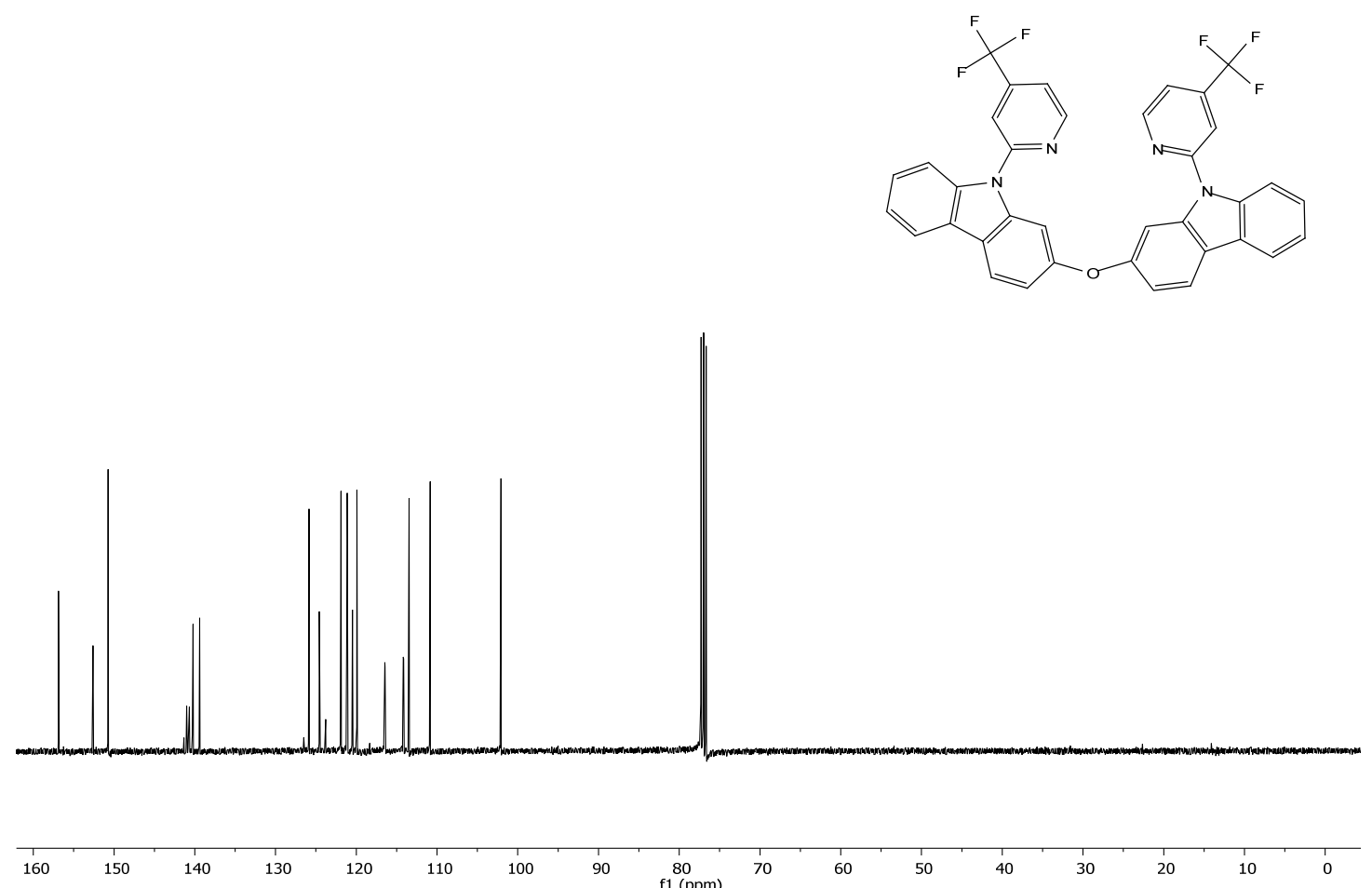

Figure S13: ${ }^{13} \mathrm{C}-\mathrm{NMR}$ spectrum of $\mathbf{4 d}$ in $\mathrm{CDCl}_{3}$ 


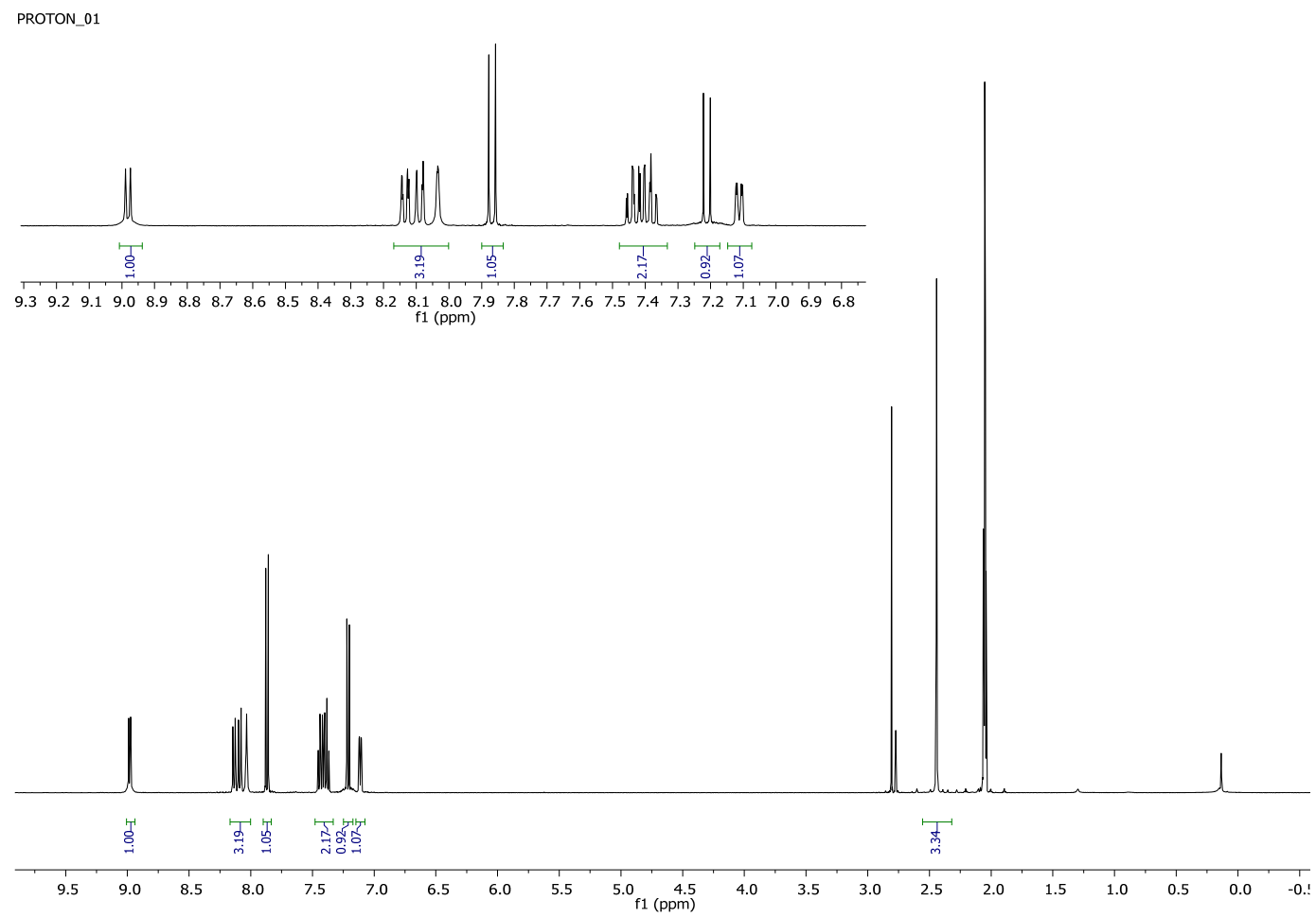

Figure S14: ${ }^{1} \mathrm{H}-\mathrm{NMR}$ spectra of $\mathbf{5 b}$ in acetone-d

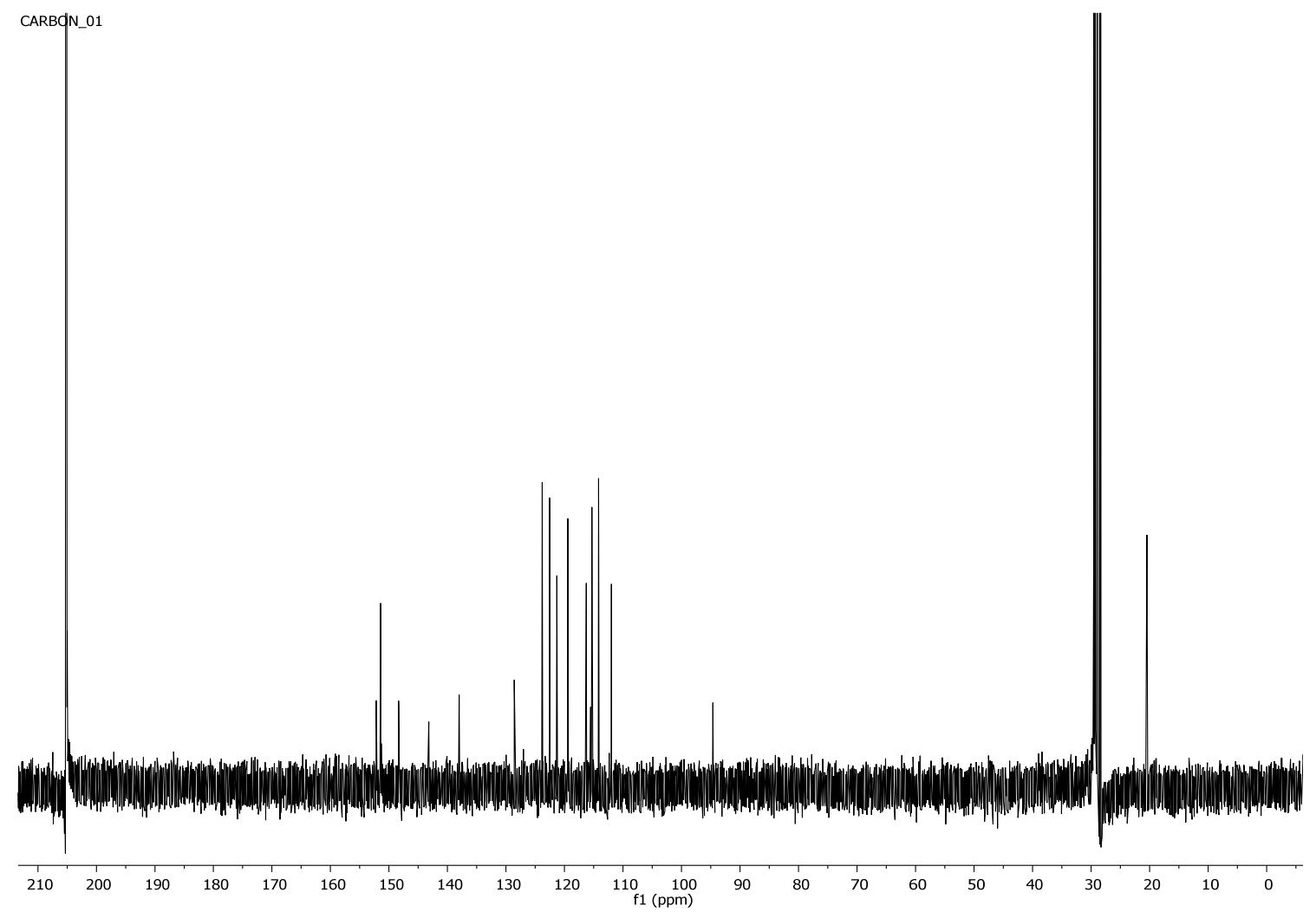

Figure S15: ${ }^{13} \mathrm{C}-\mathrm{NMR}$ spectrum of $\mathbf{5 b}$ in acetone-d 


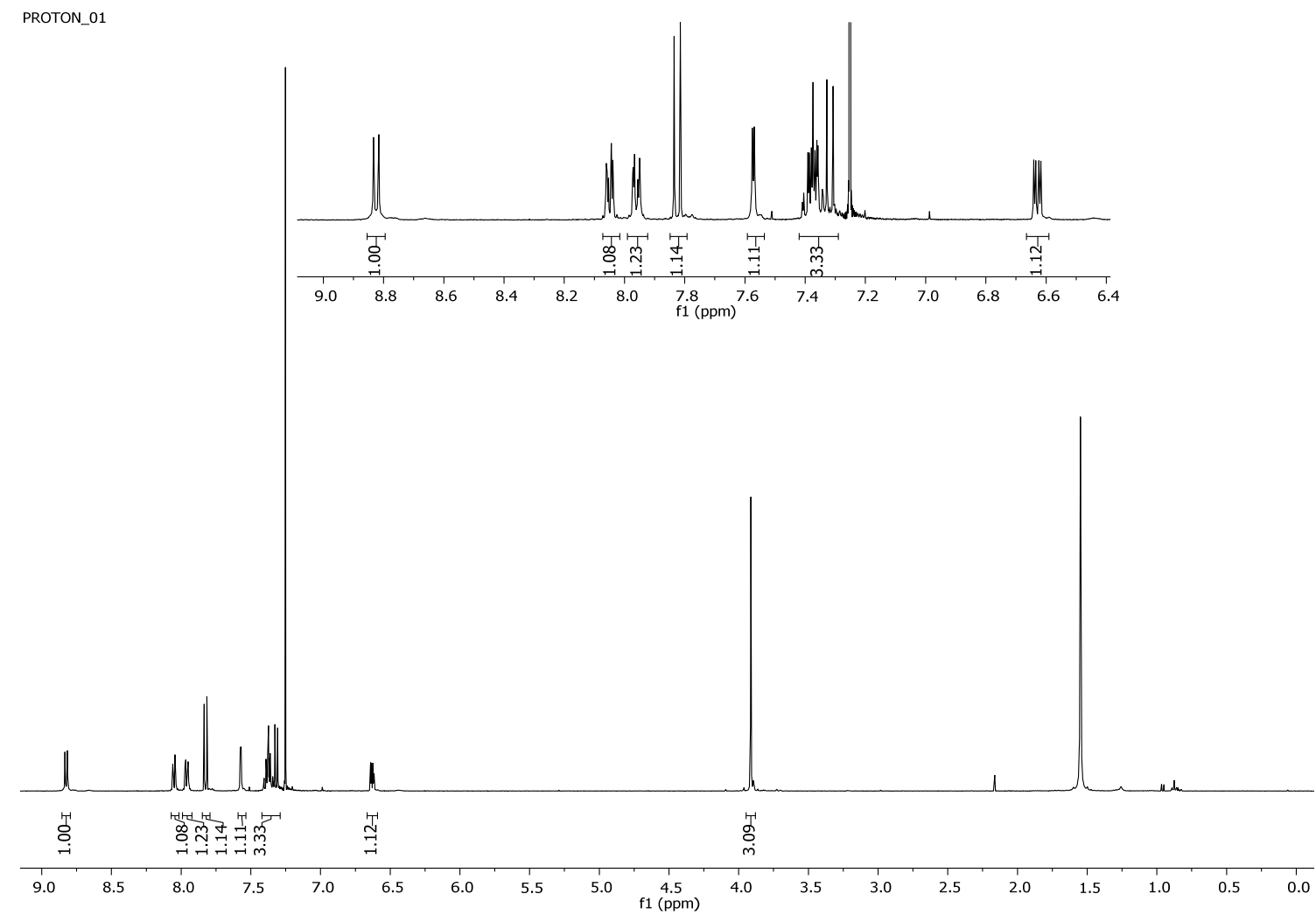

Figure S16: ${ }^{1} \mathrm{H}-\mathrm{NMR}$ spectra of $\mathbf{5 c}$ in $\mathrm{CDCl}_{3}$

CARBON_01

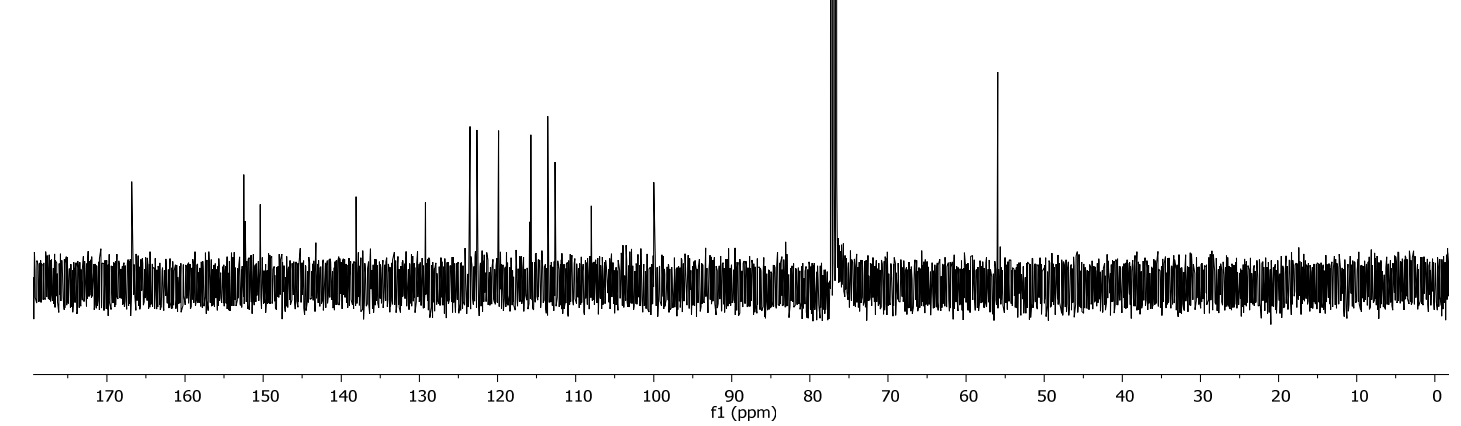

Figure S17: ${ }^{13} \mathrm{C}-\mathrm{NMR}$ spectrum of $\mathbf{5 c}$ in $\mathrm{CDCl}_{3}$ 


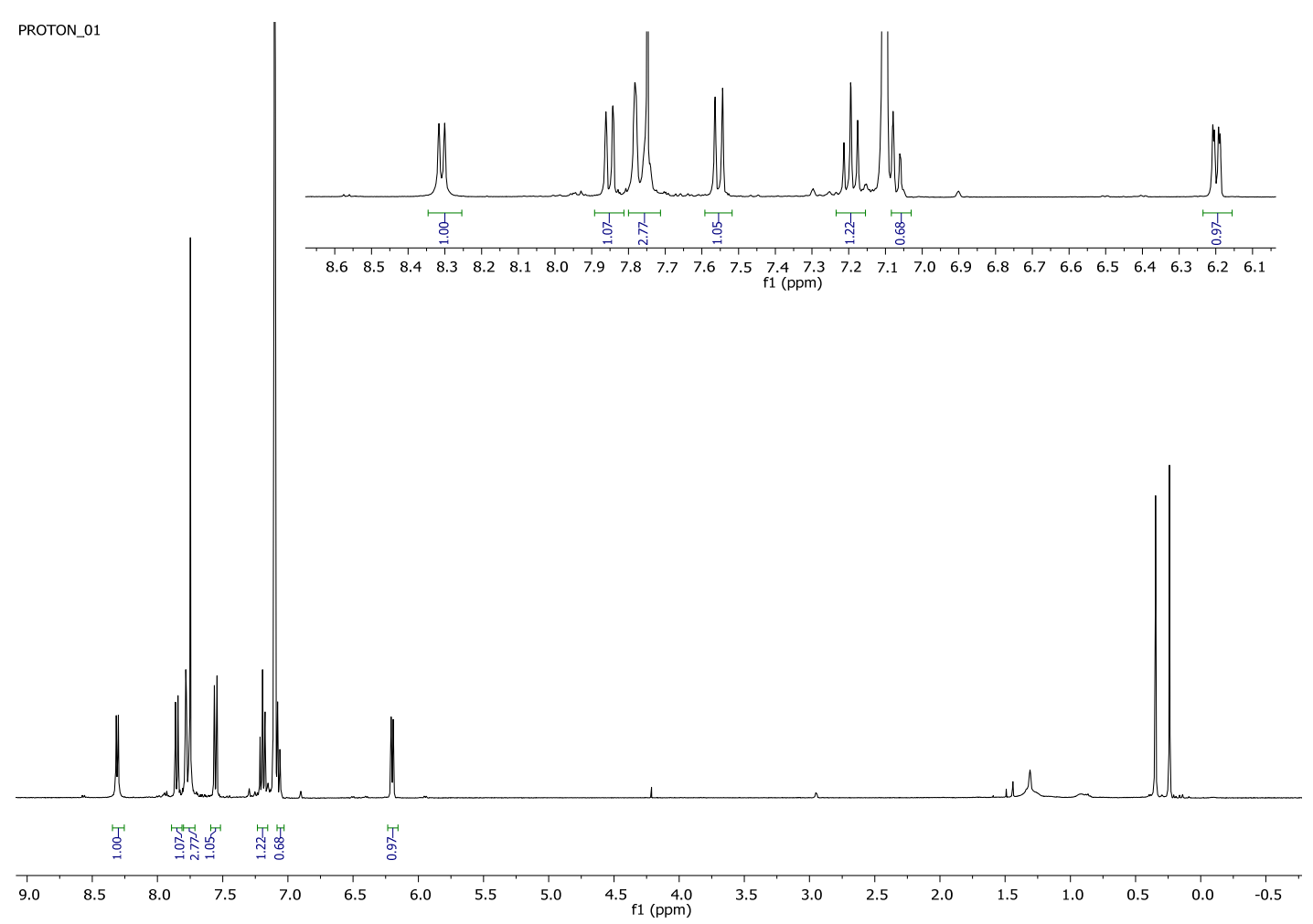

Figure S18: ${ }^{1} \mathrm{H}-\mathrm{NMR}$ spectra of $\mathbf{5 d}$ in $\mathrm{C}_{6} \mathrm{D}_{6}$

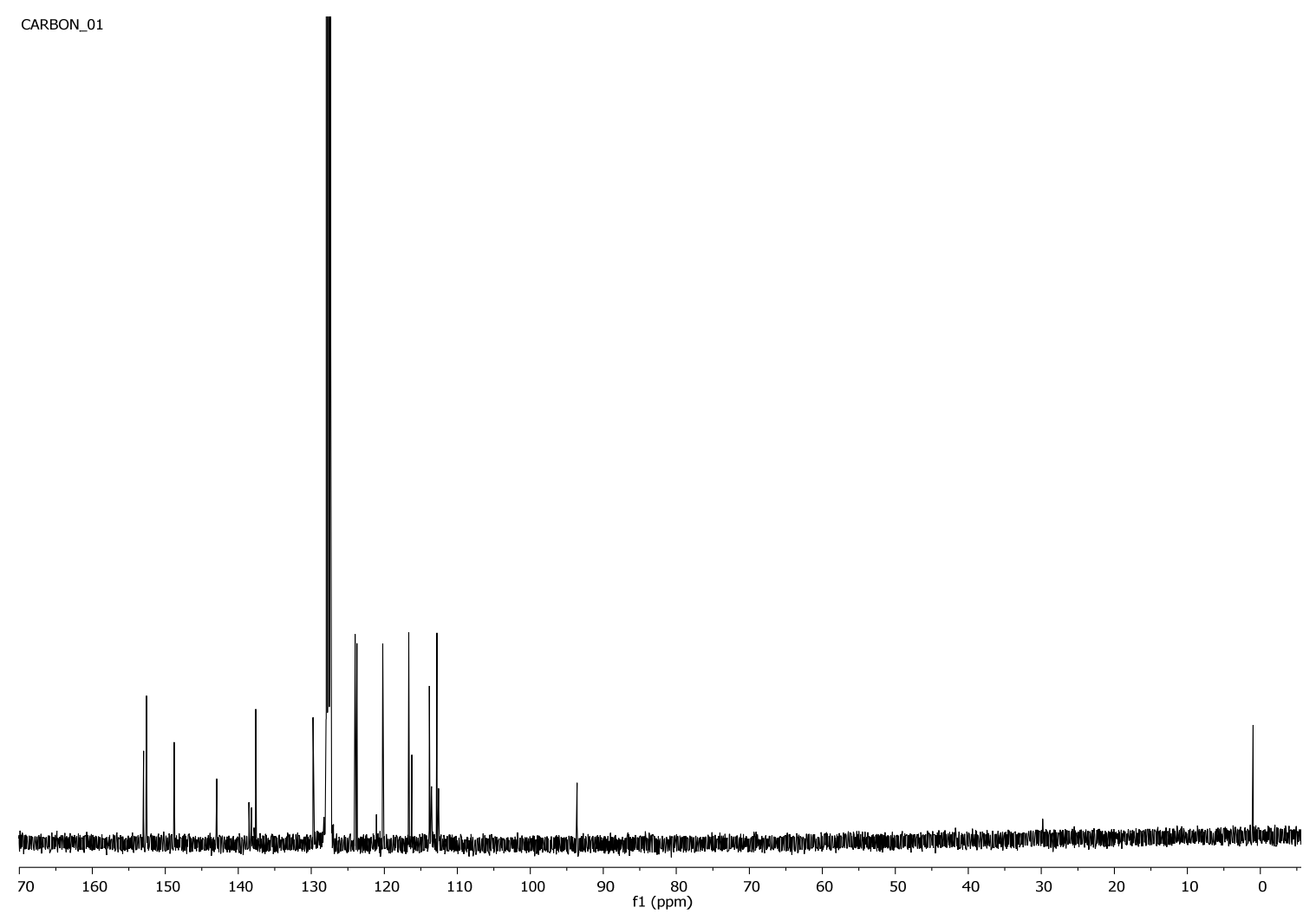

Figure S19: ${ }^{13} \mathrm{C}-\mathrm{NMR}$ spectrum of $\mathbf{5 d}$ in $\mathrm{C}_{6} \mathrm{D}_{6}$ 


\section{Mass Spectroscopy}

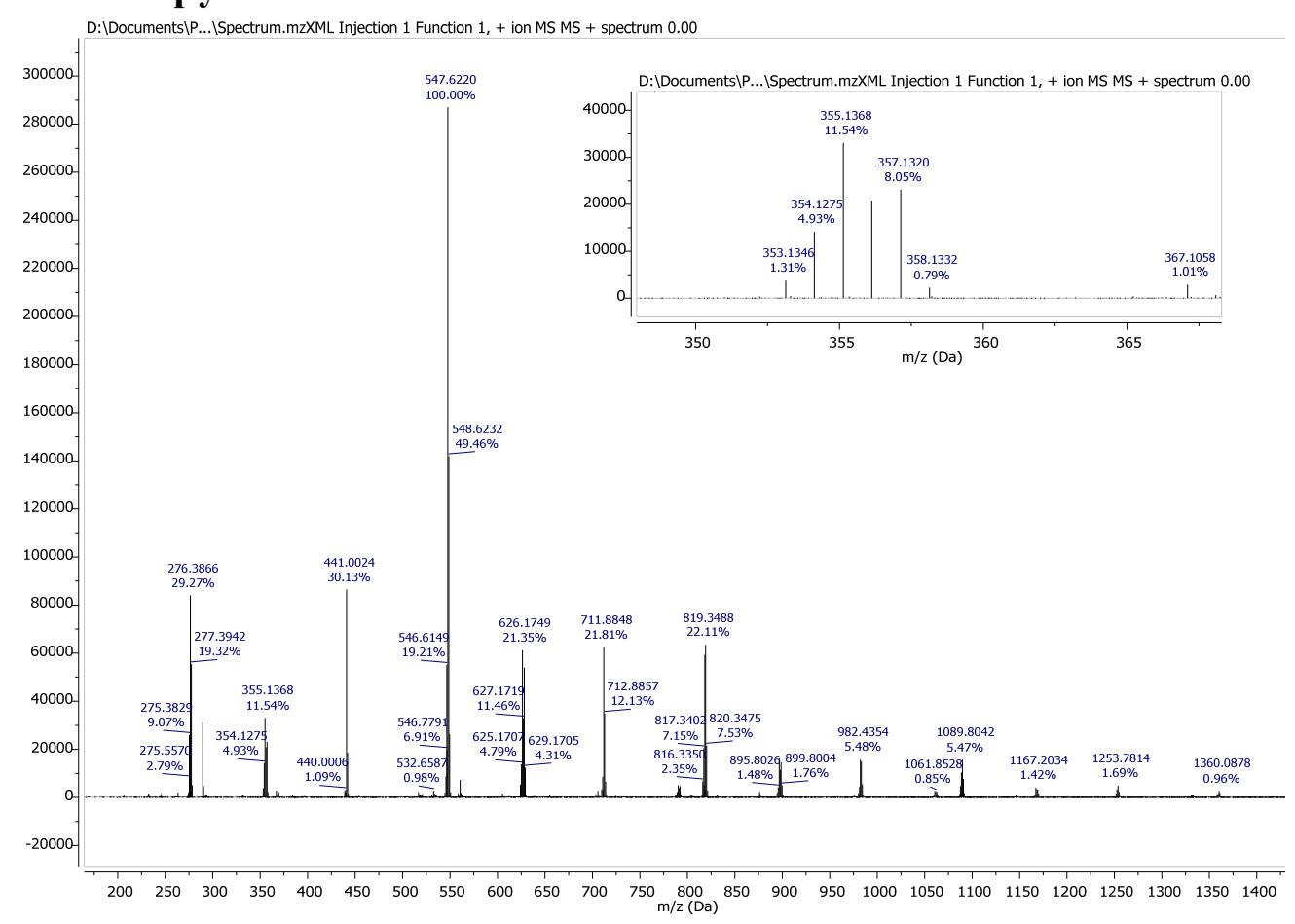

Figure S20: MALDI-TOF spectrum of 2c

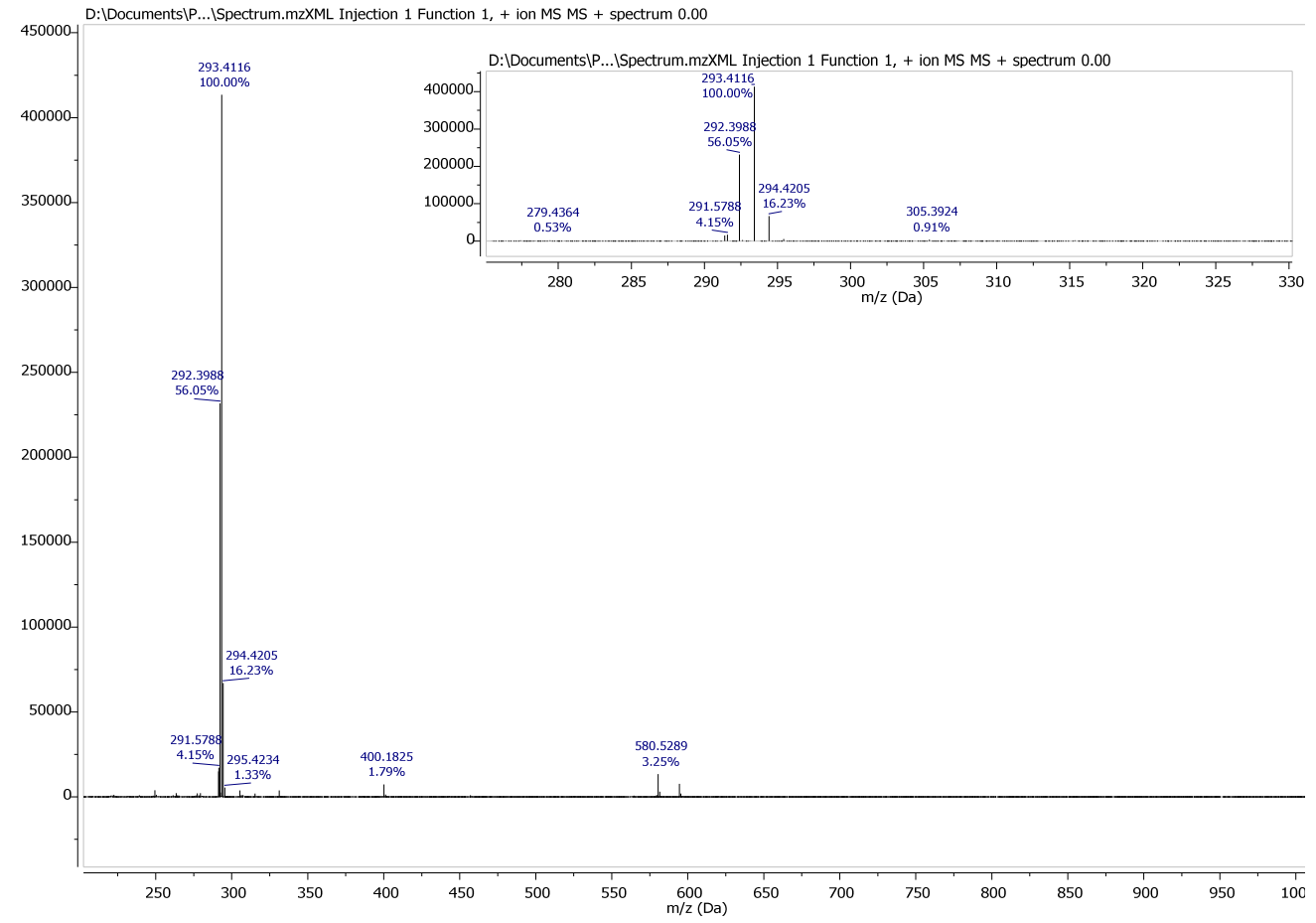

Figure S21: MALDI-TOF spectrum of $\mathbf{3 c}$ 


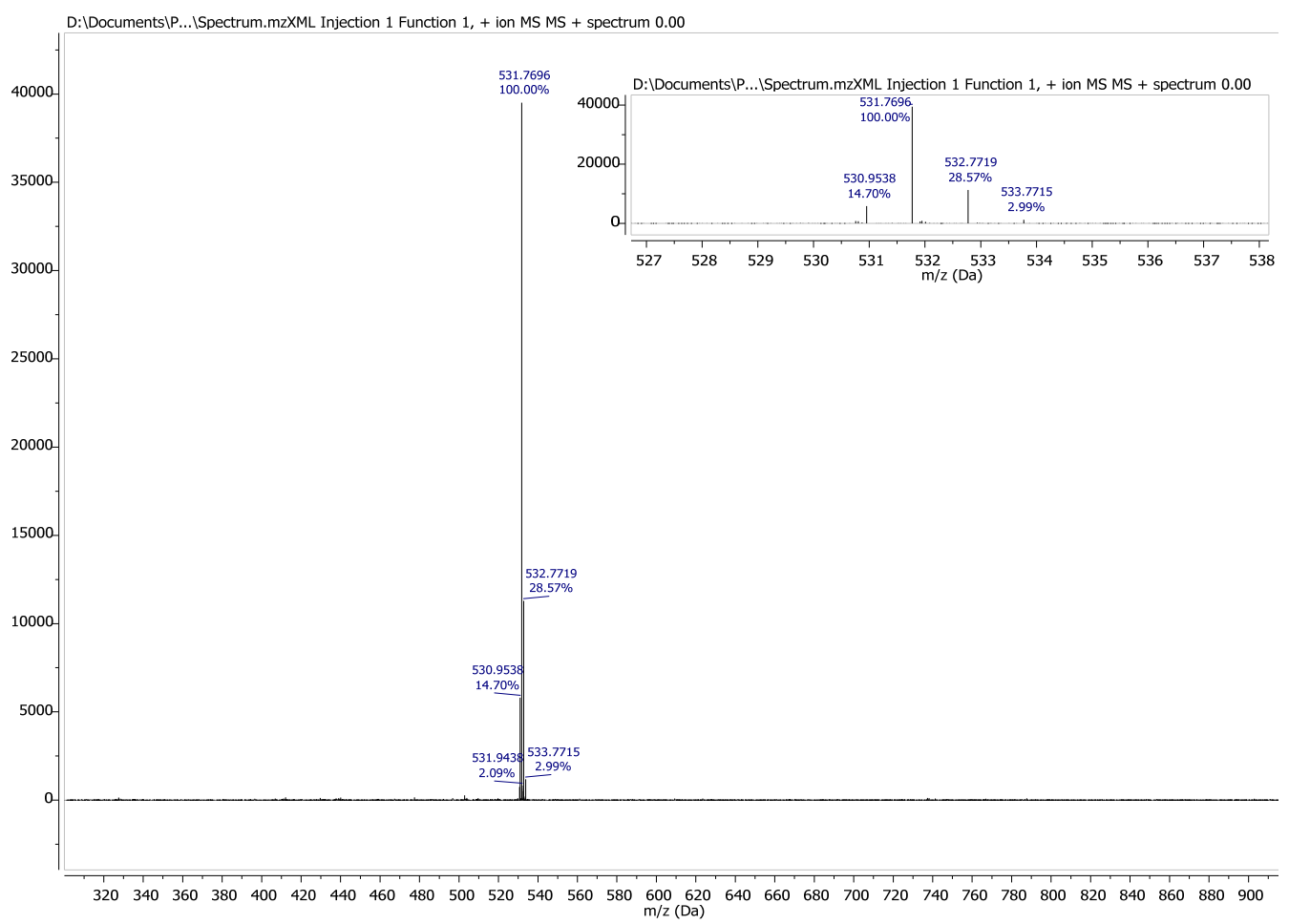

Figure S22: MALDI-TOF spectrum of $\mathbf{4 b}$

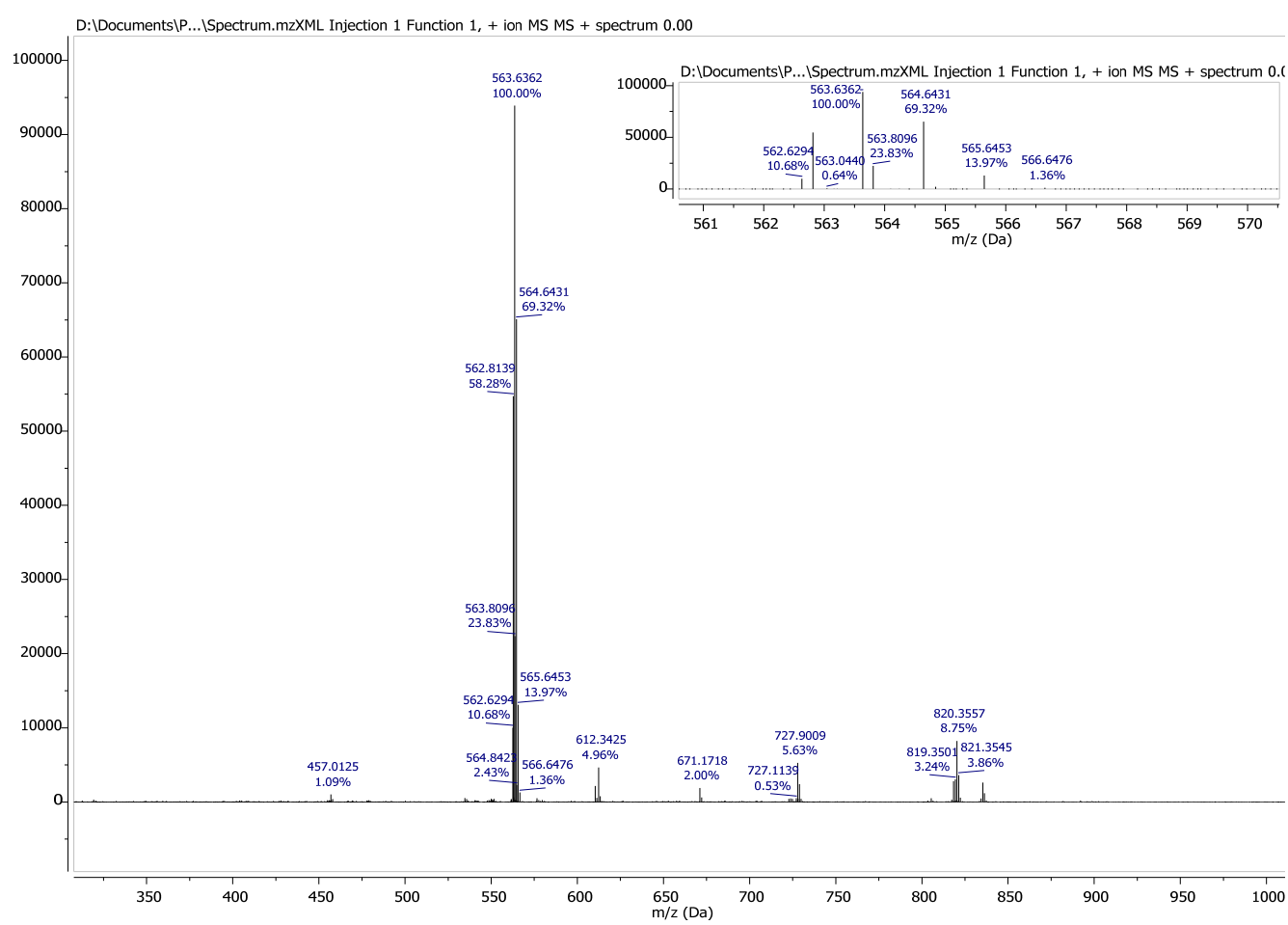

Figure S23: MALDI-TOF spectrum of $\mathbf{4 c}$ 


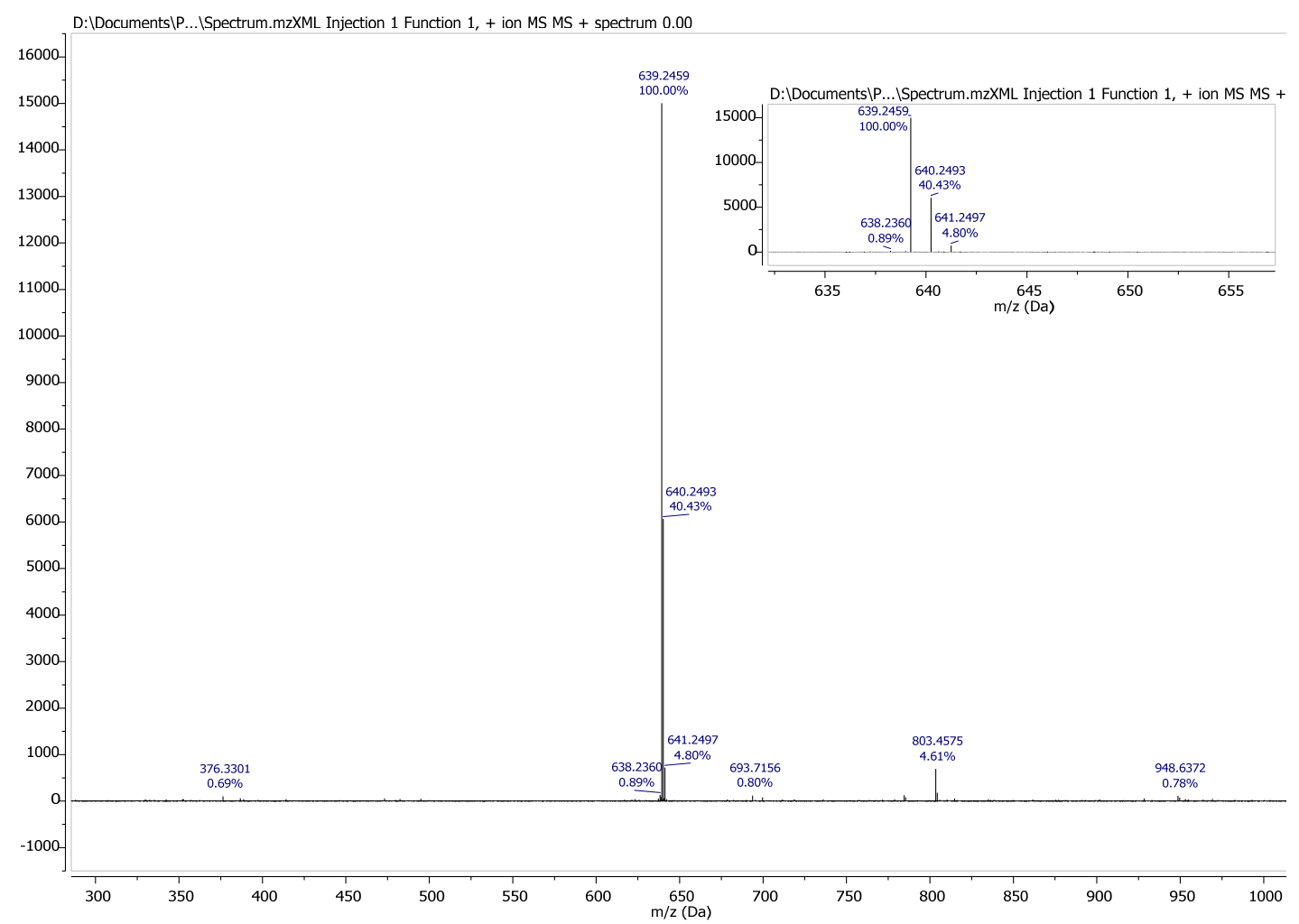

Figure S24: MALDI-TOF spectrum of $\mathbf{4 d}$

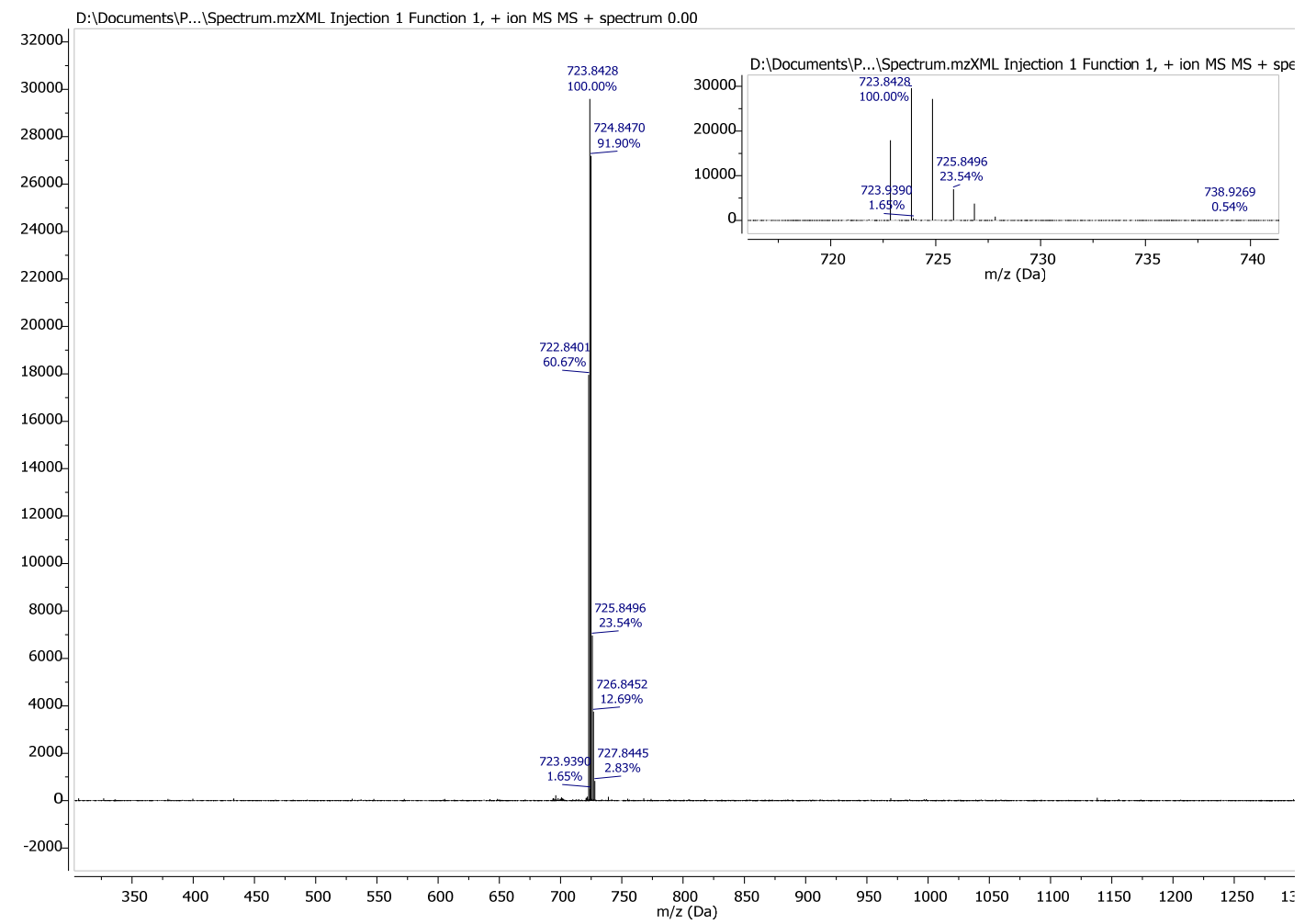

Figure S25: MALDI-TOF spectrum of $\mathbf{5 b}$ 


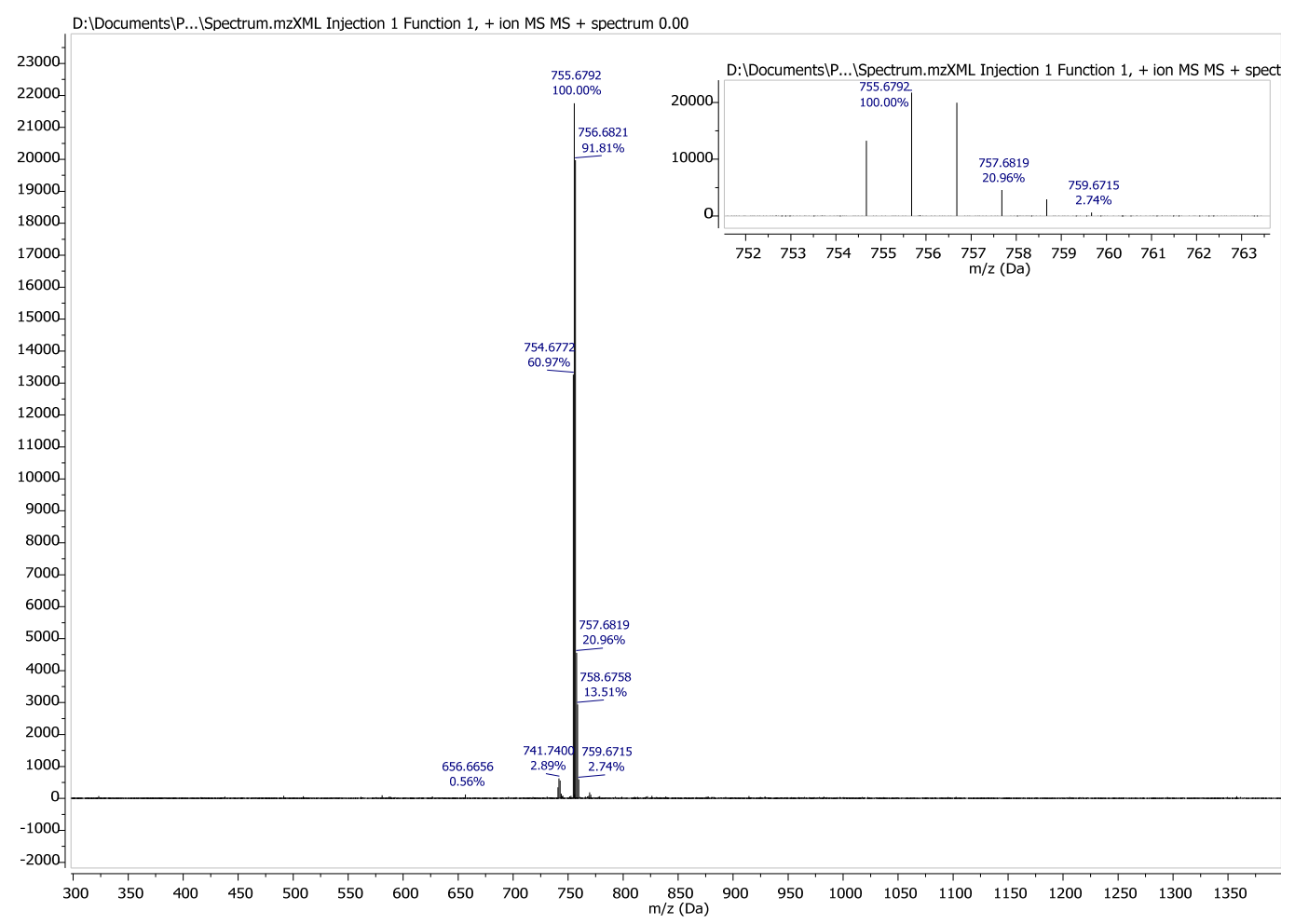

Figure S26: MALDI-TOF spectrum of $\mathbf{5 c}$

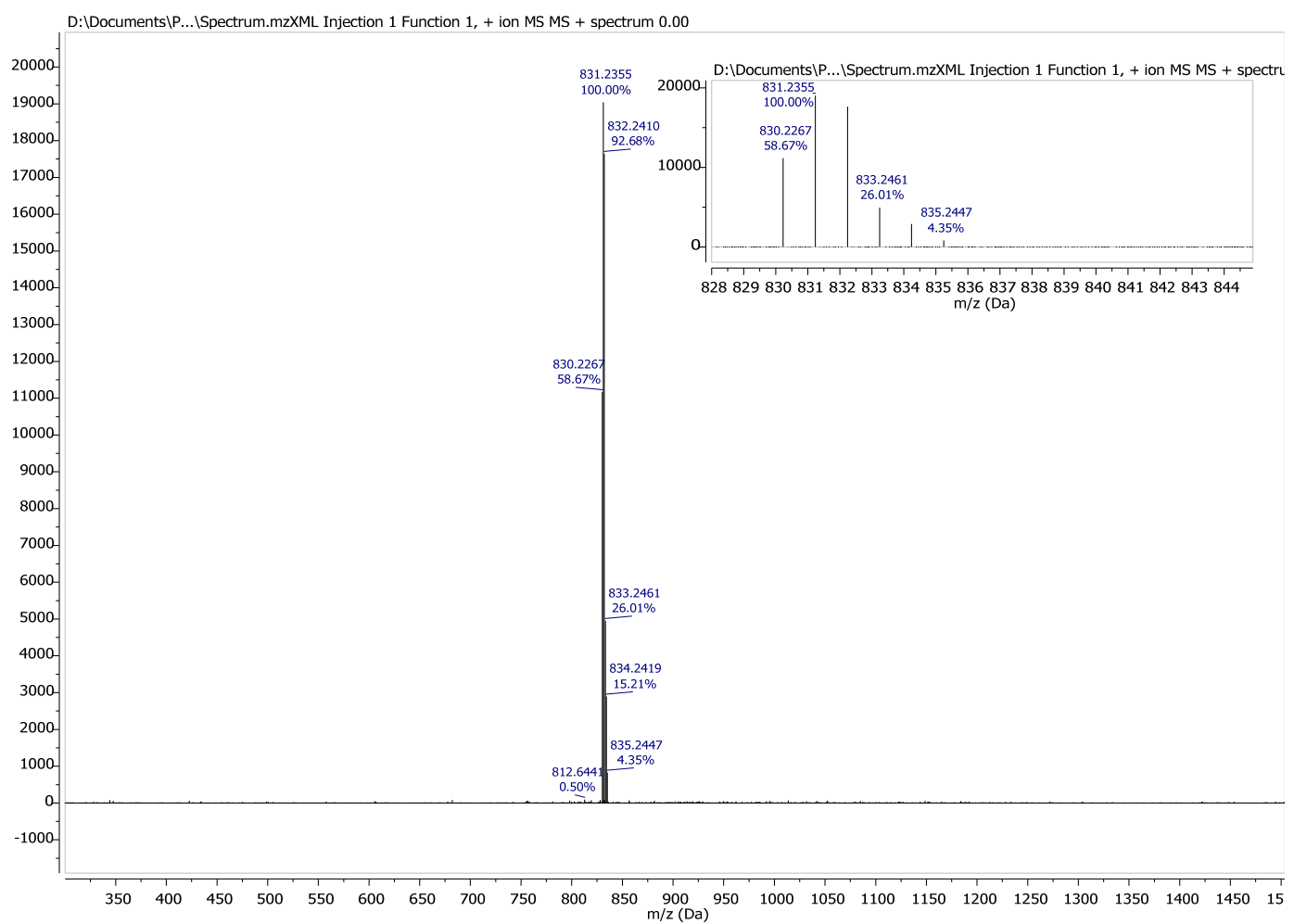

Figure S27: MALDI-TOF spectrum of 5d 